\title{
2 To Remember and Understand New Knowledge Using Online Educational Resources
}

\subsection{Introduction}

As explained in Section 1.2.1, the focus of the first and second levels of Bloom's taxonomy is on remembering and understanding new knowledge. In this chapter, my goal is to introduce several online educational resources that you may find useful to achieve goals in these levels. See Figure 2.1 for a general overview of the chapter.
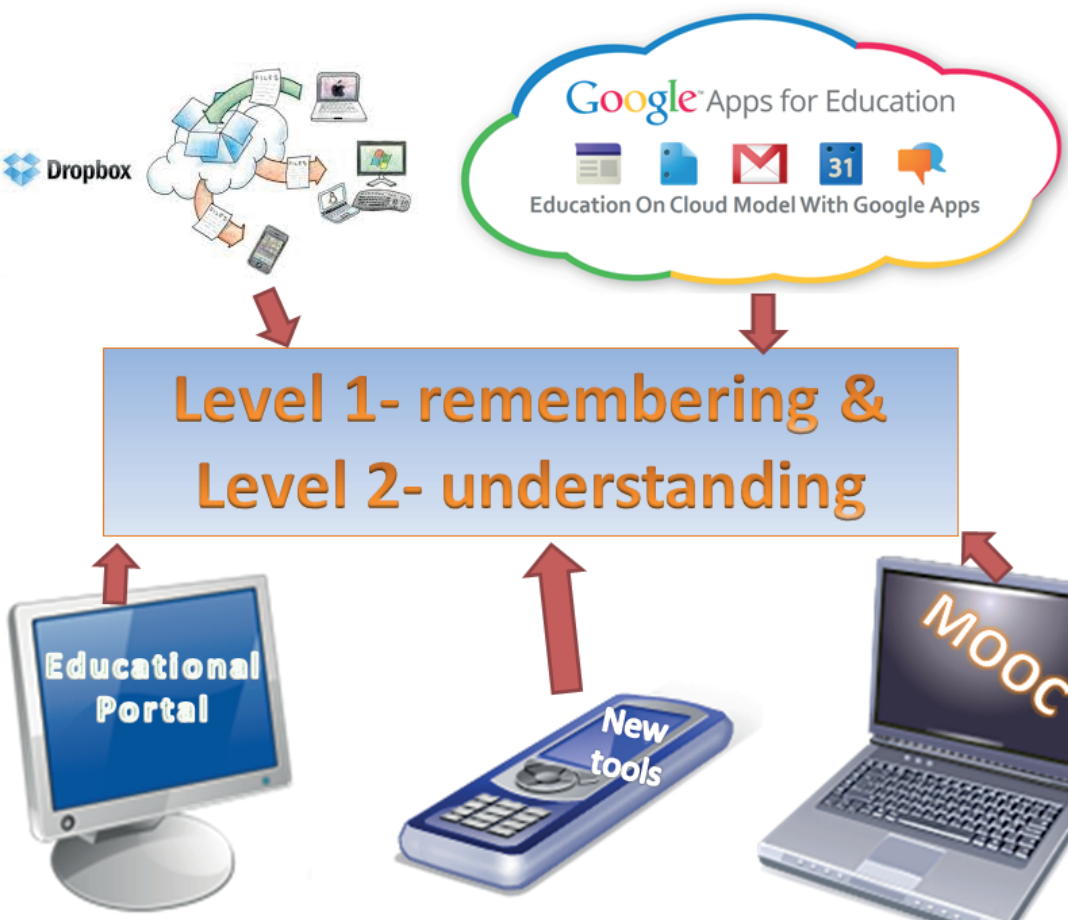

1- remembering \&
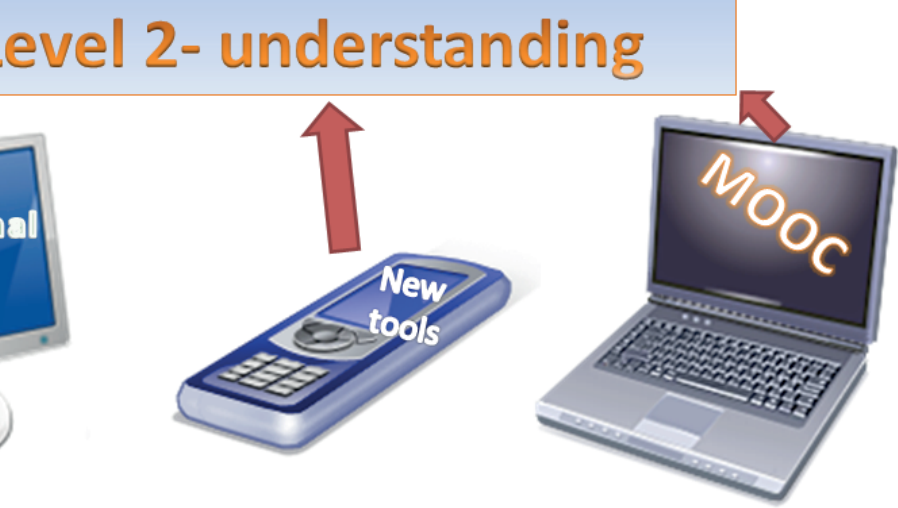

Figure 2.1: General overview of chapter 2 (tools for levels 1 \& 2 of Bloom's taxonomy)

The resources described in this chapter have been chosen because, from my experience, I have had the opportunity of checking that students are able to use them, and that they are tools that serve to accomplish the formulated pedagogical goal. Another reason is that they are free, and I can give you a step-by-step guide to their use. Please, do not think that these are the only resources available on-line, 
they can change, and there are many more possibilities, this is just to get you started and give you the basic knowledge and skills to keep working!

As you get familiar with these tools, I am sure you will be able to find others that you can find even more useful for your particular case. Moreover, you will be able to create your own resources. So, let's start with the possibilities of Educational Portals in Section 2.2, their evolution to Massive Open On-line Courses (MOOC) in Section 2.3, some on-line Google Resources for Education in Section 2.4, and Dropbox in Section 2.5. The chapter ends, as always, with several solved exercises. Remember that this book is not a novel, and that you must practice what you read in order to take advantage of it!

\subsection{Education Portals}

\subsubsection{Definition}

The Internet is a huge source of information. However, you cannot believe everything published on the web. Education Portals are websites created by the education community for the education community. These websites offer many services and a lot of content. For example, tools to find knowledge, didactic resources, collaboration tools, counselling, and even fun activities so that your students learn while they are having a good time (Bedriñana-Ascarza, 2005).

So, just by looking at this definition, if I ask you to go to http://education-portal. com/, take care, this is a tricky question, would you tell me whether that website is an education portal?

Well, the answer is no. An education portal is not only a repository of courses. Does this mean that this site is not useful? Not at all, we will learn in Section 2.3 about the concept of massive open on-line courses, and how some education portals have evolved to become huge repositories of these courses. However, there are still many education portals able to offer a range of services and content to accomplish goals in levels 1 and 2 of Bloom's taxonomy that I would like to share with you.

So, let's study in detail which features are needed so that you can be really sure that you have found an education portal. To do that, please read again the definition provided for education portals in the first paragraph. It says that an education portal must be a website. However, we have just seen that not all websites are education portals as you can also see in Figure 2.2. 




University

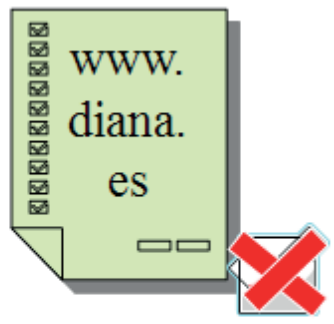

Personal webpage

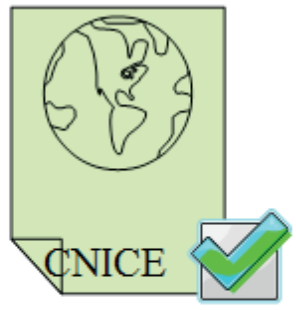

Website for teachers

Figure 2.2: An education portal is a website, but not all websites are education portals

If we keep reading the definition, it says that an education portal must provide services. A service is an activity offered to serve a certain need of the users of the portal (usually students, teachers, or parents). Some sample services are the following:

- A search engine: It allows users to write one or more keywords to get specific information about the topics in the educational portal related to these keywords (see Figure 2.3)

- Communication tools: It allows users synchronous communication (e.g. a chat, all users must be connected at the same time) and asynchronous communication (e.g. a forum).

- Training: It provides links to courses and other didactic resources for students, teachers, parents, etc.

- Counseling: It gives advice about the most appropriate content and activities according to certain criteria (e.g. pedagogical criteria).

- Fun: It provides educational games so that students can individually or collaboratively play to study concepts and competences.

e.g. if a polynomial.

\section{polynomial}

e.g. If a polynomial..

\section{Polynomials are...}

Figure 2.3: An education portal must provide services, e.g. a content search engine 
There is no minimum (well, one!) or maximum list of services that an education portal must provide to be considered an education portal. So, is Gmail an education portal?

Well, the answer is again no, because although Gmail is a website and if offers services, it does not meet the most important requisite, read the definition again: education portals are created by the education community for the education community. This is a very powerful requisite. Not anyone can create an education portal. Usually, there is an institution or at least a group of teachers behind it. This assures the quality of the material, and involves more teachers, students, parents, and even companies that would like to offer some free content. On the other hand, because the content is usually free, and there is no contract, some education portals maintained by teachers depend on their amount of free time and efforts to update the portal. Thus, sometimes the education portal disappears, or to be able to afford the website hosting, many adverts are published, these can be really annoying. This is the reason why I will try to focus your attention on educational portals supported by institutions. Figure 2.4 shows a sample education portal supported by the Harvard Community ${ }^{6}$.

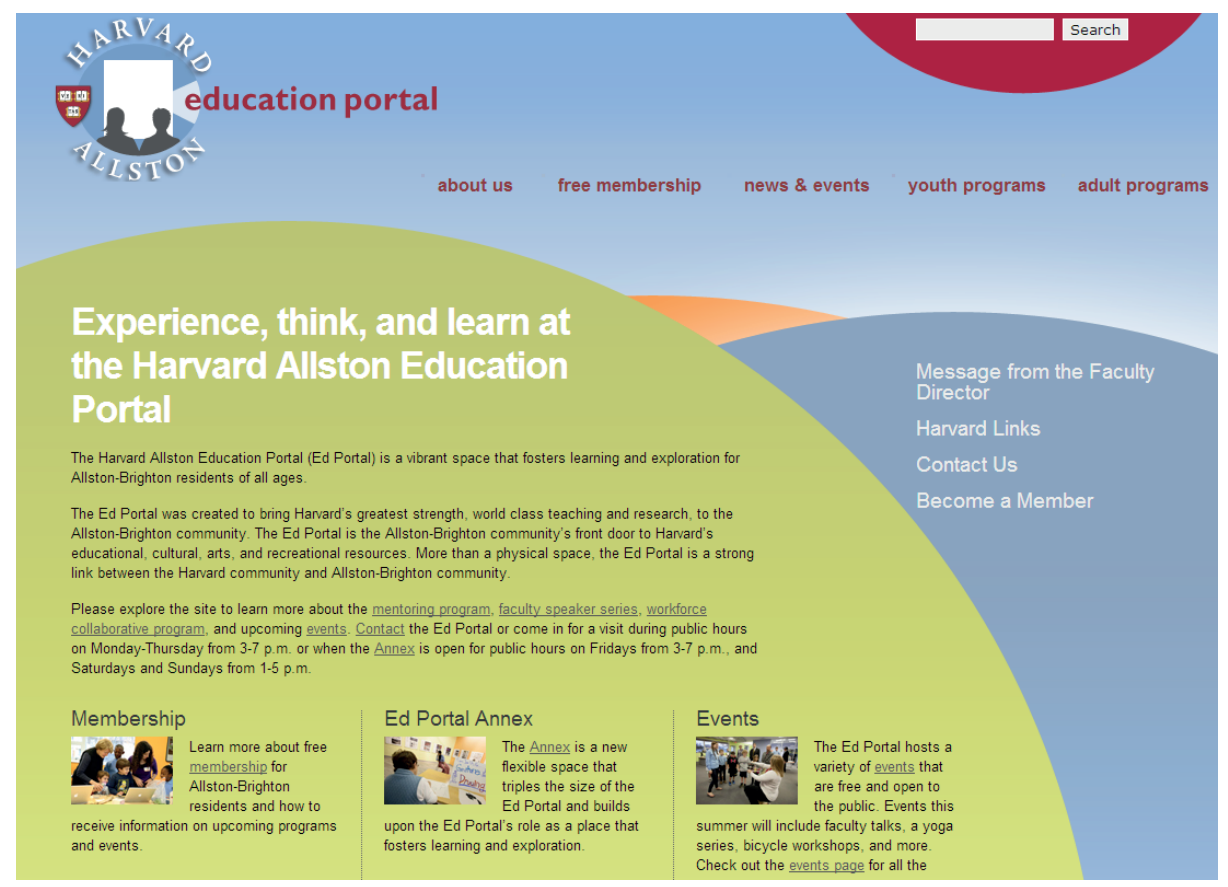

Figure 2.4: A sample education portal (website, with education services and contents)

6 See http://edportal.harvard.edu/, last visit August 2nd, 2013. 


\subsubsection{Features}

The main features of an education portal are the following:

1. There must be didactic resources (about several general topics or a specific topic).

2. The knowledge must be organized according to features of the users such as:

a. Role: student, teacher, parent, etc.

b. Area of knowledge: biology, language, chemistry, etc.

c. Age: children, young people, life-long learning, etc.

d. Language: English, Spanish, German, etc.

3. It must be self-contained, i.e. without dependencies on external links.

4. It must provide added value services.

So, let's pick the sample education portal shown in Figure 2.4, and find the features indicated:

1) Where are the didactic resources? Well, it seems that there is no specific topic of knowledge, instead it seems be a general education portal. It is OK. So, this general knowledge must be organized according to certain criteria, if we look on the right upper corner, we can find two interesting links regarding didactic resources "youth programs" and "adult programs". Let's click on "adult programs". Have you already done it? What do you see? I see something like Figure 2.5, can you see the same? (if not, do not worry it is the Internet, it is possible they just updated the website!)

My first advice here is that you always have a look around the webpage. Get familiar with the links, they usually group other possibilities. If you cannot see what you are looking for at the beginning, do not worry, keep exploring, the computer is not going to break, and once you practice with several education portals, you will start finding common patterns, such as, looking on the upper menu, or using the search engine located on the right upper corner marked in green (see Figure 2.6).

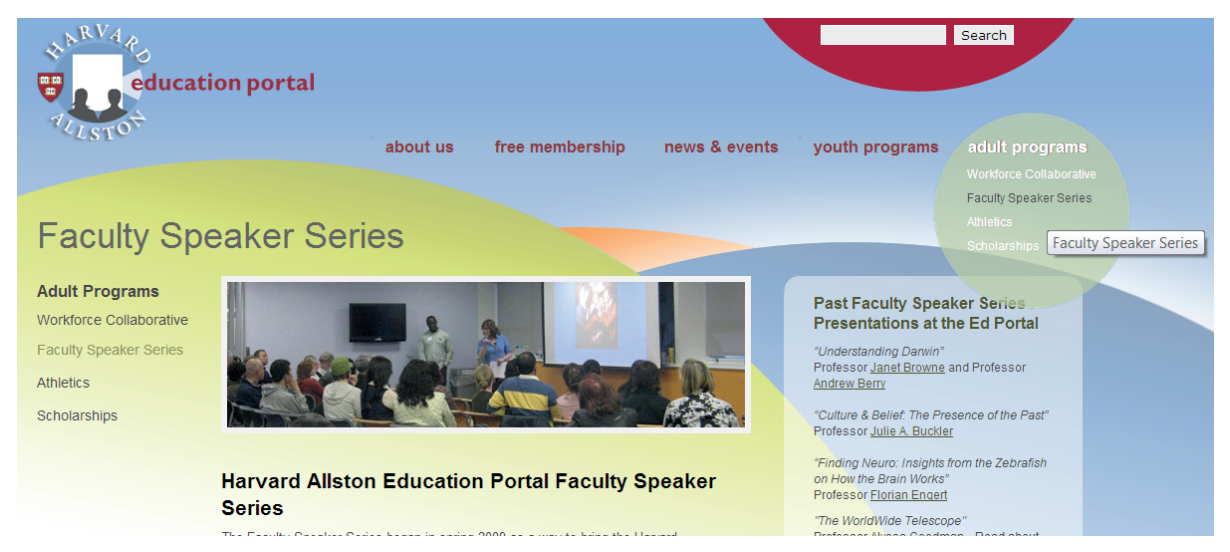

Figure 2.5: Some didactic resources found in the sample education portal 


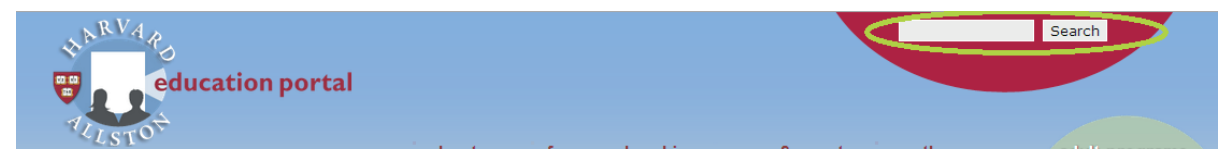

Figure 2.6: The search engine to help you find information in the education portal

And, another question, do you know what happens when you click on the logo on the left? Let's try! Have you tried it? Yes, you did it! You went back to the home page. This is another useful tip whenever you start exploring so much, you do not know how to come back. In those cases, again, do not worry just click on the logo (usually on the upper left corner) and the website usually will go back to the home webpage, just like that!

OK, so we found a faculty speaker series, it seems interesting! We could keep exploring how to download them if they are free to download, or just view them on the webpage. Remember that the third feature is that the education portal should be self-contained, so usually it does not redirect you outside (although it may happen in some cases, nothing is $100 \%$ perfect, in those cases if there is no logo to click and go back, you can just use the "Go back" option of the browser, copy again the link or even better save the links that you find interesting as bookmarks so that you can always click on them to safely go back to the home webpage).

Finally, according to the fourth feature, the education portal should provide added value services, what do you say about trying now to find those "added value services"? Let's look again at the website. See what I just found in Figure 2.7.

This time I clicked on the "Free membership" link, and I found that even if I do not live in the Allston-Brighton area, I can sign up for the Ed Portal's email list to stay up to date on what is happening there. What did you find?

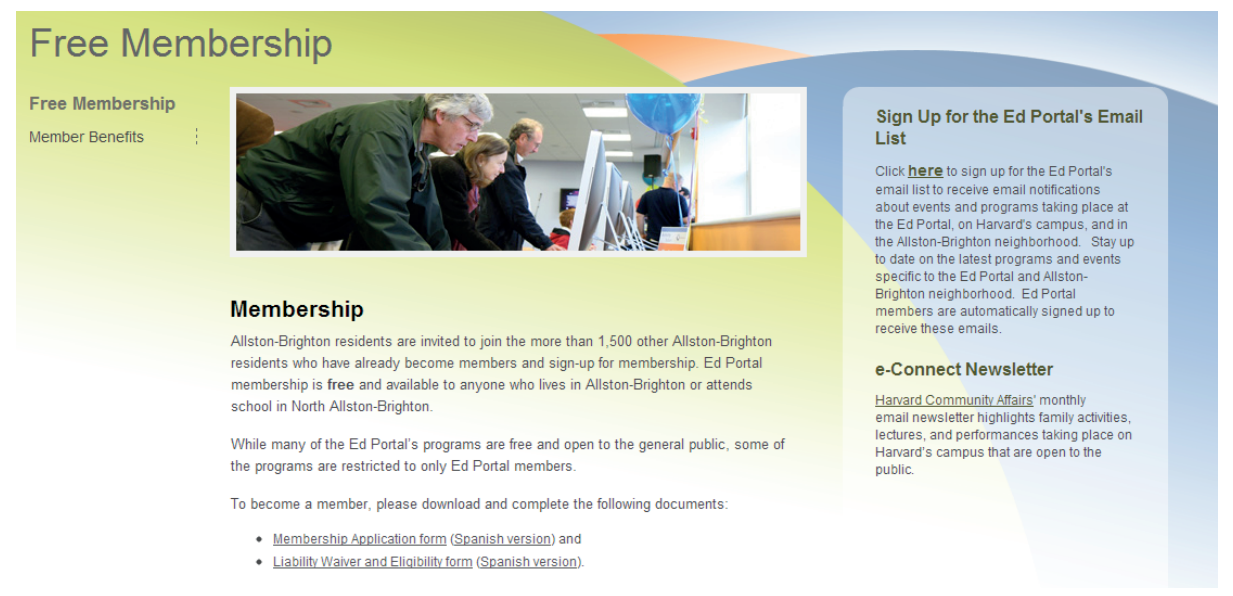

Figure 2.7: Some services provided by the sample education portal 


\subsubsection{Taxonomy and Samples}

Figure 2.8 shows a possible taxonomy of education portals according to three main criteria: the type of information provided (general or specific), the geographic scope (international, national or regional) and its informative or formative nature. Informative education portals just want to share information of an institution (institutional) or educational resources. On the other hand, formative education portals aim to virtually educate (even with virtual classrooms) or to provide didactic material.

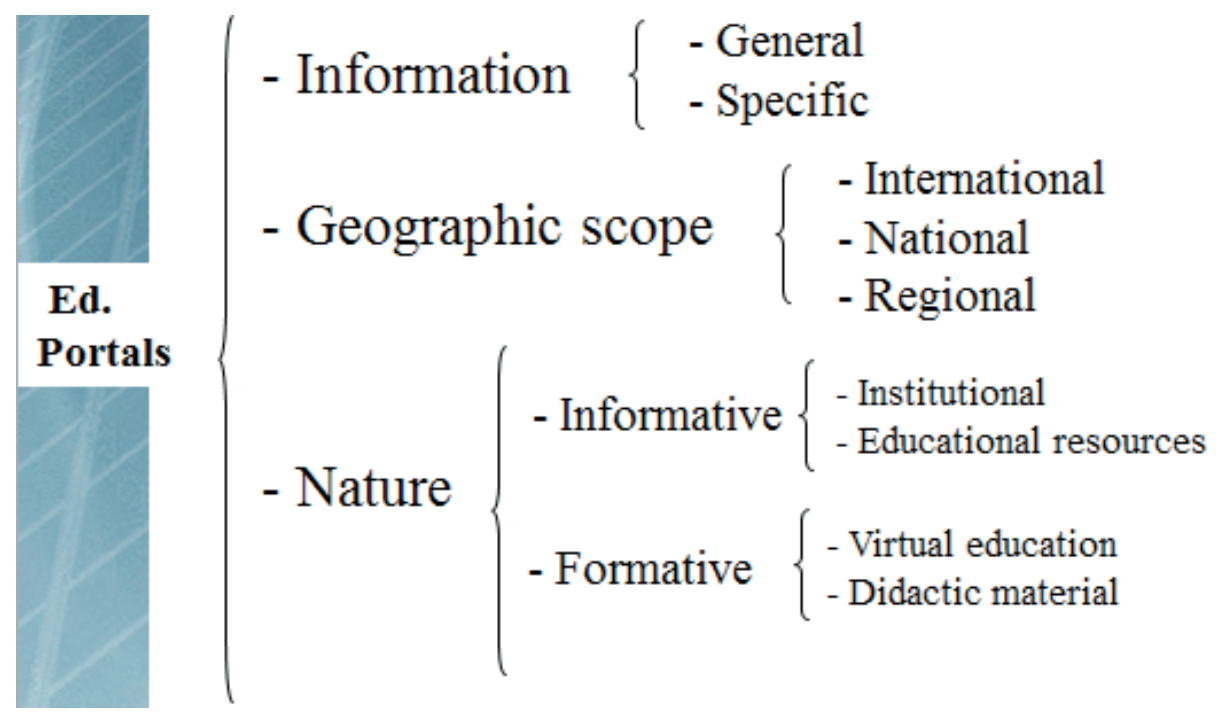

Figure 2.8: Services provided

As you can see, there are many possibilities, and my advice is that you explore many education portals at the beginning, for instance, now, explore the links provided in the references, the examples given, but later, when you are working, choose 2-3 education portals, the ones that you find more relevant for your work, and focus on those education portals. The idea is that you do not need to check every five minutes what has been updated, but just be aware that there is a huge source of free, high-quality material waiting for you in those education portals.

OK, so let's explore more education portals, classify them according to the taxonomy provided and how they can be used to accomplish levels 1 and 2 of Bloom's taxonomy. 
The first education portal that I would like to share with you is the one provided by the Oman Ministry of Education (http://www.moe.gov.om/portal/sitebuilder/sites/ eps/english/home.aspx). Have you looked at it? If the link no longer works, just try to type into a search engine like Google the keywords "oman education portal", and surely you will find the link in one of the top ten of the results. So, now you have the webpage, something similar to Figure 2.9. Again, it may have changed. Let's classify the portal:

Information: General

Geographic Scope: National

Nature: Informative, Institution - the Oman Ministry of Education

Now, let's find resources! The information is organized according to categories, so if we click on "students" we can find, for instance, some "studying tips". It is now time for you to explore more options of this education portal. Enjoy it!

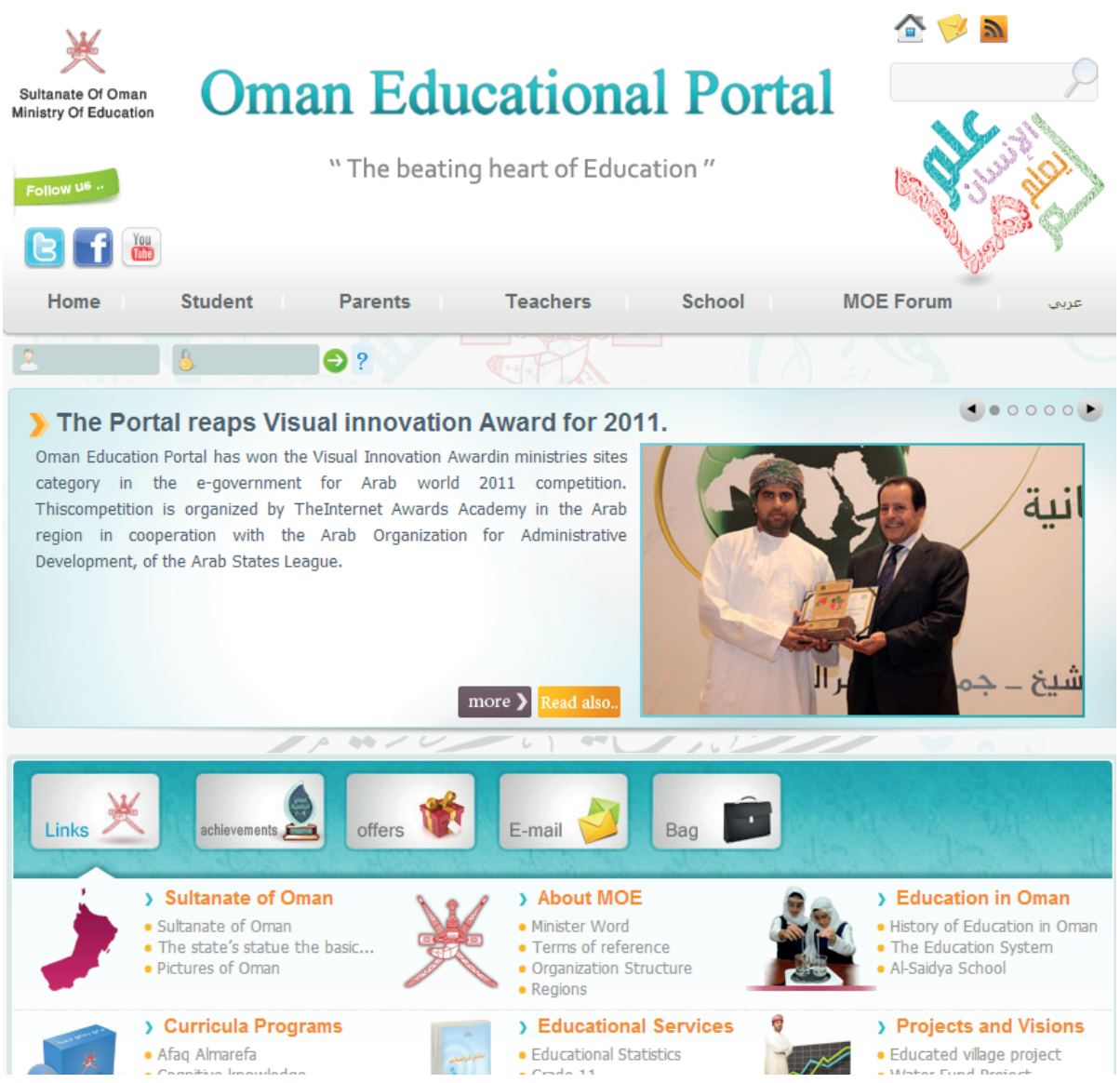

Figure 2.9: Oman Ministry of Education portal 
The second education portal that I would like to share with you is the one provided by the New Zealand Transport Agency (http://education.nzta.govt.nz/), which you can see in Figure 2.10. Let's classify the portal:

Information: Specific (road safety)

Geographic Scope: National

Nature: Informative, Educational Resources

Moreover, if we click on "resources" we can find, for instance, by clicking on "secondary curriculum resources" some "case studies”. You can keep exploring more possibilities.

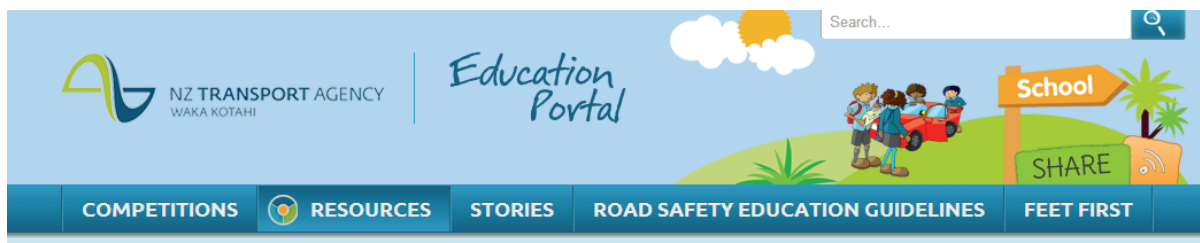

\section{NZTA curriculum and school resources}
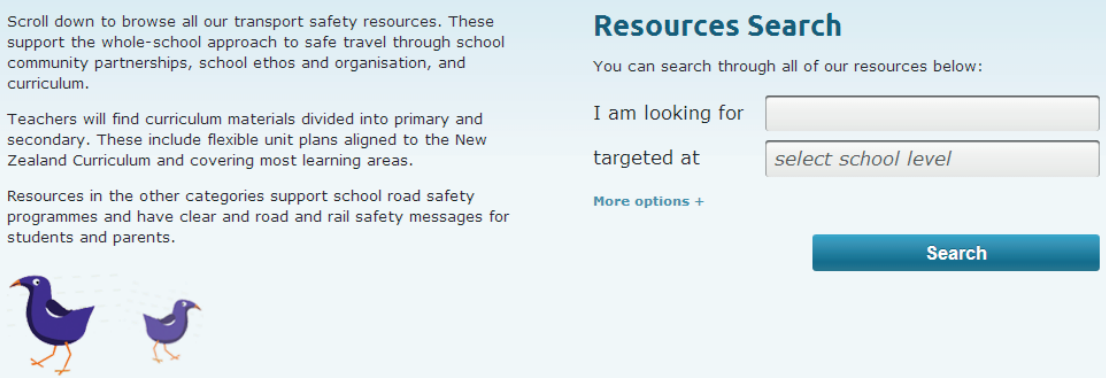

Browse Whole School Approach Sections

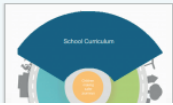

Secondary curriculum resources

Teachers can download and modify units which integrate road safety as a context into several learning areas. Set at curriculum level 4 and above. Includes several NCEA internal assessment resources, all QAAM certified by NZQA.

Figure 2.10: New Zealand transport education portal

The third education portal that I would like to share with you is the international Education World portal (http://www.educationworld.com/), which you can see in Figure 2.11. Let's classify the portal:

\section{Information: General}

Geographic Scope: International

Nature: Formative, didactic materials

Moreover, if we click on "Teachers" we can find, for instance, by further clicking on "New printable back to school writing activities" some "writing assignments". 




Figure 2.11: A sample international education portal

Let's continue with a fourth education portal, the BBC education portal (http://www. bbc.co.uk/learning/), which you can see in Figure 2.12, and let's classify the portal:

Information: General

Geographic Scope: International

Nature: Formative, virtual education

If we click on "Art and design" we can find, for instance, by clicking again on "BBC Arts" some "readings". There is also a video you can watch in English with some multimedia for the reading.

Finally, let's explore a fifth education portal that is an example of a regional portal (http://kids.nypl.org/), which you can see Figure 2.13. Let’s classify the portal:

Information: Specific (literature)

Geographic Scope: Regional (New York)

Nature: Informative, Institution (New York Public Library)

If we click on "Books" we can find, for instance, a list of available audiobooks for children and the media format in which they can be listened to on the computer. 


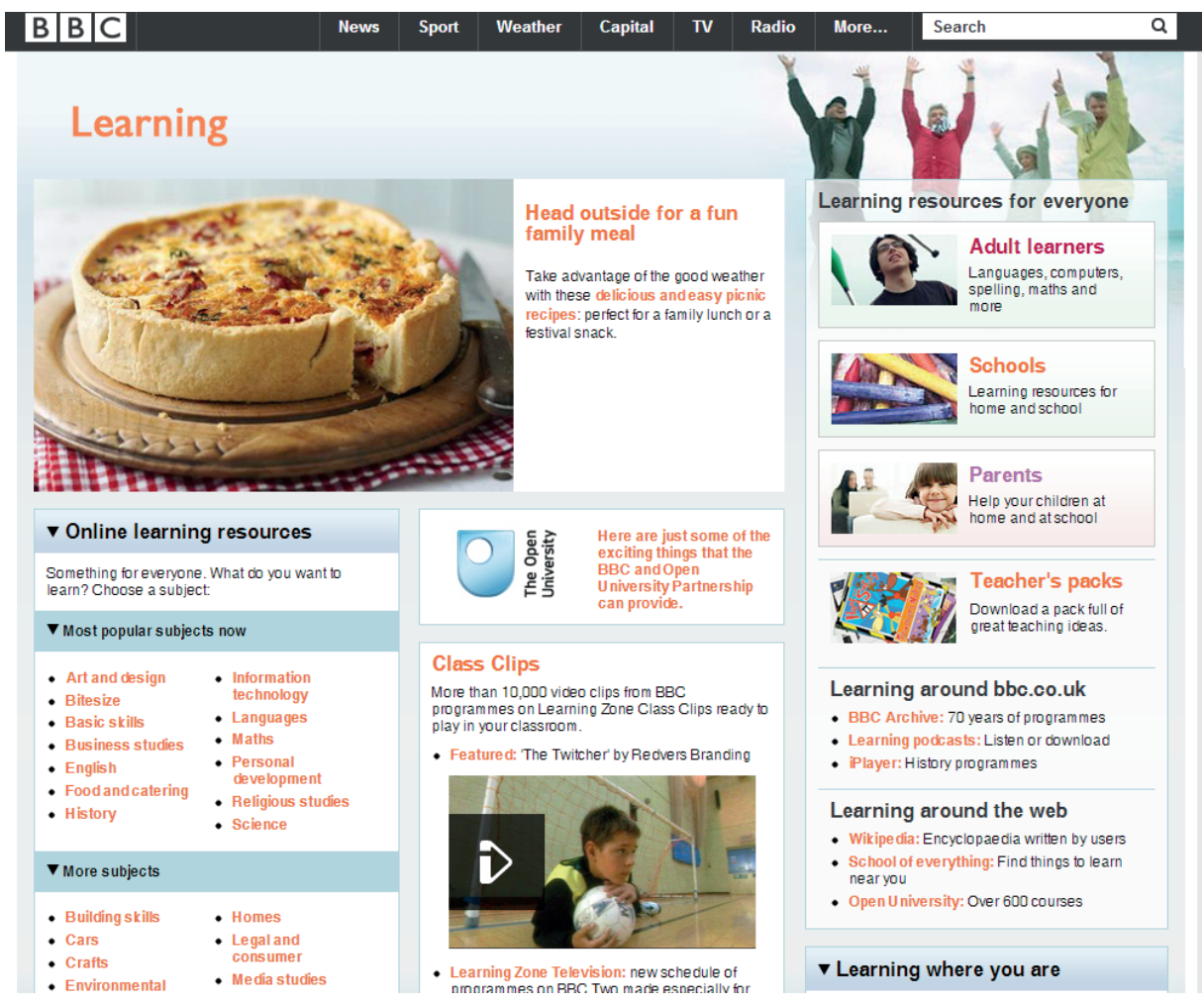

Figure 2.12: $B B C$ learning education portal

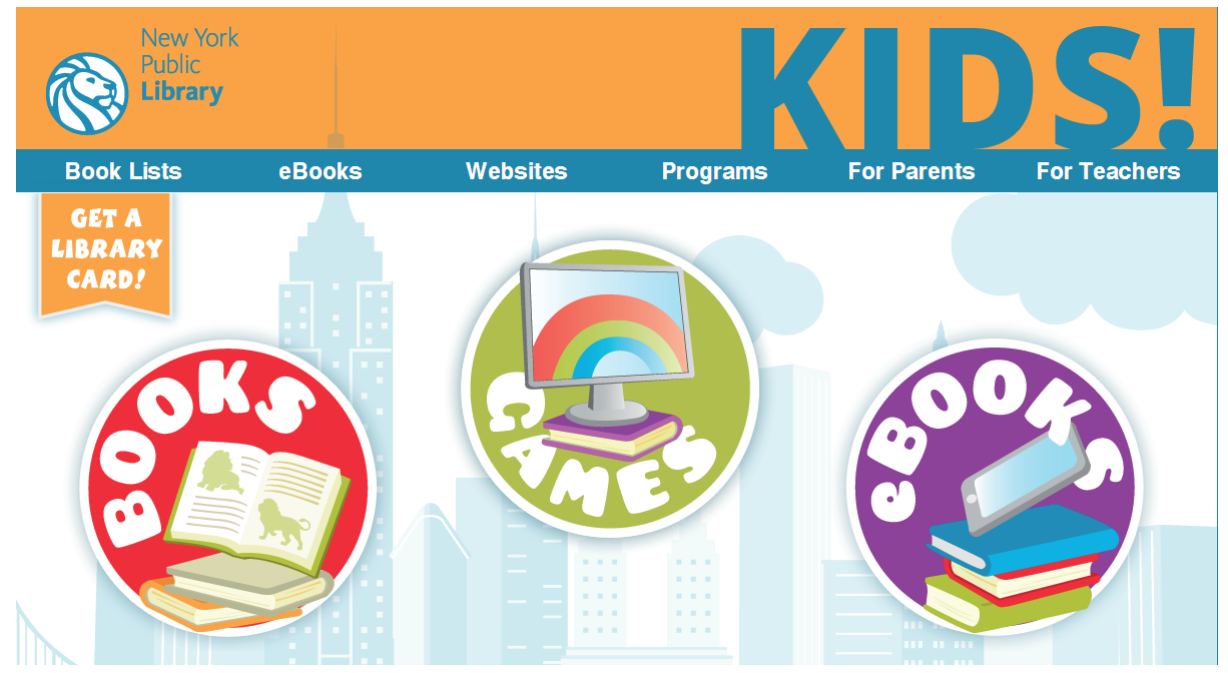

Figure 2.13: Sample regional education portal 


\subsection{MOOCs}

\subsubsection{Definition}

According to McAuley et al. (2010) a MOOC (Massive Open On-line Course) is "an on-line phenomenon that integrates the connectivity of social networking, the facilitation of an acknowledged expert in a field of study, and a collection of freely accessible online resources". If we compare this definition to the one provided for education portal in Section 2.2.1, we can see there are some similarities such as: both are online education resources, and both were created by the education community. However, there are several important differences:

1. Education portals do not necessarily include courses in which thousands of students enrol, study, and complete assignments.

2. Education portals do not necessarily include the connectivity of social networking. Given that they were created earlier, usually chat-rooms, newsletters and forums are the key collaborative tools. On the other hand, given that MOOCs were created later, since 2010-2011 (Daniel, 2012), social networks are key elements, bringing with them new possibilities for collaboration.

3. MOOCs are like the evolution of some education portals, as they now offer full courses, with the possibility of interacting with other students all over the world, and having a teacher, an expert in the area of knowledge, as facilitator of the course.

As I said earlier, teachers in MOOCs do not have the same role that teachers have in class. No teacher is able to follow the conversations and homework of thousands of students at the same time! Teachers in MOOCs become facilitators, they provide questions to the group, high quality resources and sometimes they check the social networking tools to provide general questions.

Some new issues in MOOCs are how to certify the learning made by those thousands of students. Usually, the evaluation is based on on-line tests, peer-to-peer assessment or answers to questions in a forum, but still there is no consensus as to whether it would serve as university credits or as merits for a job interview. Many MOOCs offer on-line badges that certify the work done by the student, without the signature of the teacher, and recently some institutions offer some signature and even, if the course is not free, some university credits.

Another issue in MOOCs is the high attrition rate (Daniel, 2012). Many students just enrol because they want to read some material, but they do not intend to follow the course or complete the tasks requested. The problem is that in many MOOCs if you do not pass one lesson, the materials of the next lesson may be blocked, so the student just drops out. In other cases, students want to pass the course, but they need to learn how to self-organize their time, to meet the deadlines, and even with the help of the social network and the computer platform which usually highlights the deadlines and events, they do not master the skill to complete all the tasks required. 
Figure 2.14 shows a MOOC in Coursera, one of the repositories of MOOCs available on-line ${ }^{7}$. As can be seen, it also provides resources, but they are not organized as in education portals, but as courses. In this particular case, the course is about the history of humankind.

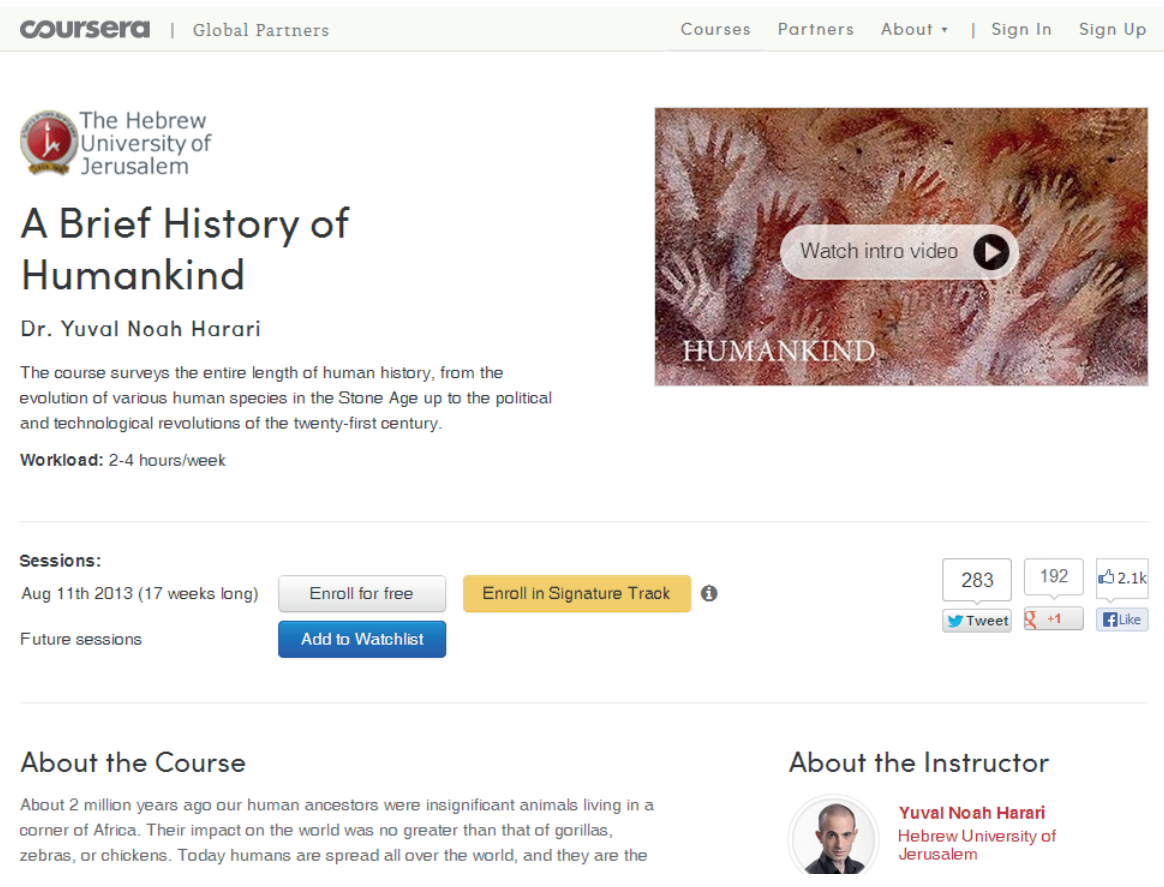

Figure 2.14: Sample MOOC

\subsubsection{Features}

The main features of a MOOC are the following:

1. The course must be created by an expert or a group of experts in the area of knowledge.

2. The knowledge must be organized in lessons (with multimedia material, usually learning goals are accomplished with short videos) and tasks to do such as: a. On-line tests, with feedback so that students can learn from their mistakes.

7 See https://www.coursera.org/course/humankind (if you cannot find it, because it has changed, any other course there will be similar and would serve as an illustrative sample of MOOC for this chapter) 
b. Answer questions from a video, or discuss the topic in an online forum.

c. Peer-to-peer assessment, such as read other students' work and comment on it.

3. It must be self-contained, i.e. without dependencies on external links.

4. It must have some social network tools to facilitate collaboration among students and with the teachers.

So, let's pick the sample MOOC shown in Figure 2.14, and find the features indicated:

1. Who is the expert behind this MOOC? Well, it we click on his name, we can read his biography, and discover that he has written several books on the topic, and that he is a member of staff at a university.

2. OK, so let's check the organization of the course, we can read in the webpage that the course syllabus includes 17 lessons organized into four parts. Each lesson is about 60-120 minutes long, divided into 3-6 short segments. It is also indicated that students can watch each lecture in one session, or break it up into several segments. No readings are necessary, it seems than the tasks are watching the videos and reading the materials for about 2-4 hours per week.

3. The course is self-contained, if we click on "Enroll" when the date of the beginning of the course approaches we will be told by mail or social network, and we will be able to start the course for free. There is also a new possibility. That is, to enroll with a signature track, in which, if you pay the amount indicated, you will receive a certificate as shown in Figure 2.15

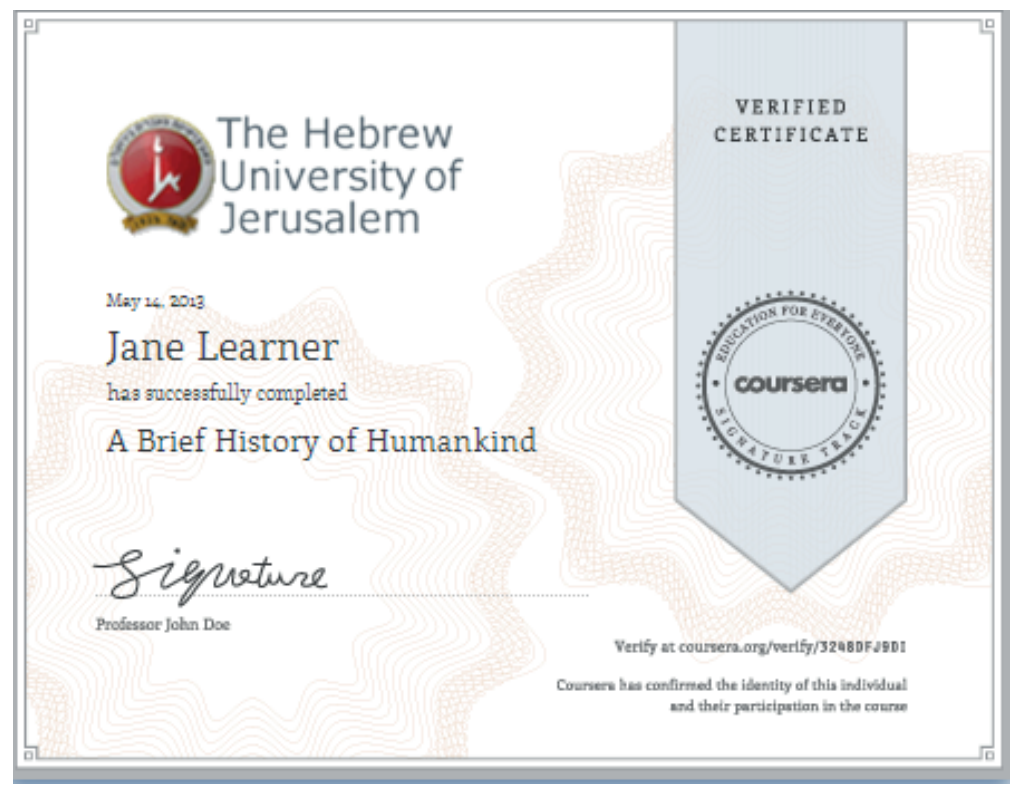

Figure 2.15: Sample certificate after passing a MOOC 
Finally, according to the fourth feature, the education portal should provide social network tools to foster collaboration among students. If we go back to Coursera, we can see how all MOOCs have links to Twitter ${ }^{8}$, Google Plus ${ }^{9}$ and Facebook ${ }^{10}$.

\subsubsection{Some Repositories of MOOCs}

OK, so how can you take full advantage of one of these MOOCs? My advice is to find a repository of MOOCs such as Coursera ${ }^{11}$ (we will provide a step-by-step guide in Section 2.3.4). Other MOOC repositories are $\operatorname{Edx}^{12}$ and Udacity ${ }^{13}$. In Spanish, there are also two important MOOC repositories: MiriadaX ${ }^{14}$ and Unedcoma ${ }^{15}$.

Once you are in the repository, you will see hundreds of MOOCs that you can study, but be patient. If you enrol in all of them, you will not be able to take full advantage of them, since you will not have time! So, my advice is similar to that provided by Koutropoulos \& Hogue (2012):

\section{1) Before the MOOC starts, ask yourself "Is this the right MOOC for me?"}

You should avoid enrolling in a MOOC just because you like the title, or you think that it might be interesting. It usually leads to drop out. It is much better to read the description of the course in full, watch the video that teachers usually provide as introduction, and to explore carefully the contents and tasks required, and the time that is needed to complete them.

\section{2) During the MOOC, what to do?}

Once you have enrolled in a MOOC that is of interest, appropriate for your current level of knowledge and suits the free time you have, you have to remember what I said at the beginning of the book: the MOOC is useful for levels one and two of Bloom's taxonomy because you will be offered a lot of education resources that you can read, learn and understand. However, MOOCs can also serve the higher levels, if you get more involved. So, you can just watch the videos, and listen to the explanations, that way you can accomplish goals in levels 1 and 2, and it is fairly easy to do that in a MOOC. Nevertheless, if you really want to take full advantage of the potential

8 https://twitter.com/

9 https://plus.google.com/up/search

10 https://www.facebook.com/

11 https://www.coursera.org

12 https://www.edx.org/

13 https://www.udacity.com/

14 https://www.miriadax.net/

15 https://unedcoma.es/ 
of a MOOC, you can complete the tasks, share your knowledge with colleagues in some social network and thus, accomplish learning goals in higher levels of Bloom's taxonomy, too.

\section{3) After the MOOC, stay connected!}

Once the MOOC finishes, it does not mean that you should disconnect from all the social network experiences. You have met other students with shared interests, so you can stay connected to them and be updated.

I would also advise you not to try to read everything written in a MOOC, it could end in cognitive overload. It is very important that you filter the information and contributions according to your doubts and main points of interest. That way, you can really benefit from all these courses waiting for you and your students!

\subsubsection{Using a MOOC in Coursera Step-by-step}

So, let's practise interacting with a MOOC in Coursera, step-by-step. First, open your browser and type the coursera.org webpage address. Given that my goal in this book is to teach you about how to use computer resources for education, in this case for level 1 and 2 of Bloom's taxonomy, let's say our goal is to learn about the foundations of teaching for learning.

First step: Enrol in the course "Foundations of Teaching for Learning", go to https://www.coursera.org/course/teach1 (it is possible that this course has closed when you are reading this section. Do not worry, you can enroll in any other course, the steps are the same). To do that, sign in, and click on "Enroll for free" (our goal is not get a certificate this time, just to learn). Figure 2.16 shows you how the platform has recognized me at the right upper corner, and where to click to enroll for free.

Second step: Go to class. Given that the course is already started, we can go to our first class. You can do that by clicking on the "Go to class" button as shown in Figure 2.17. If you would like to earn a certificate, you can also pay for it by clicking on "Learn more".

Third step: Agree to the honour code. This is very important in general in the Internet (netiquette), but in particular in MOOCs. You should be the one answering the tests, and taking the course, and the fact that other students cannot see your face does not mean that you are allowed to misbehave. If you consider something inappropriate in a face-to-face class, if you would not say something face-to-face, it should not be allowed on-line. So, let's agree to the honour code by clicking on the button as shown in Figure 2.18.

Fourth step: Read the welcome webpage. As in face-to-face class, when in the first day, the teacher tells you what it is expected of you in the course, and how the dynamic of the class is, in MOOC the welcome page gives you this information, as shown in Figure 2.19. I also advise you to watch any intro video, and explore the resources a little to become familiar with the MOOC and its possibilities. 


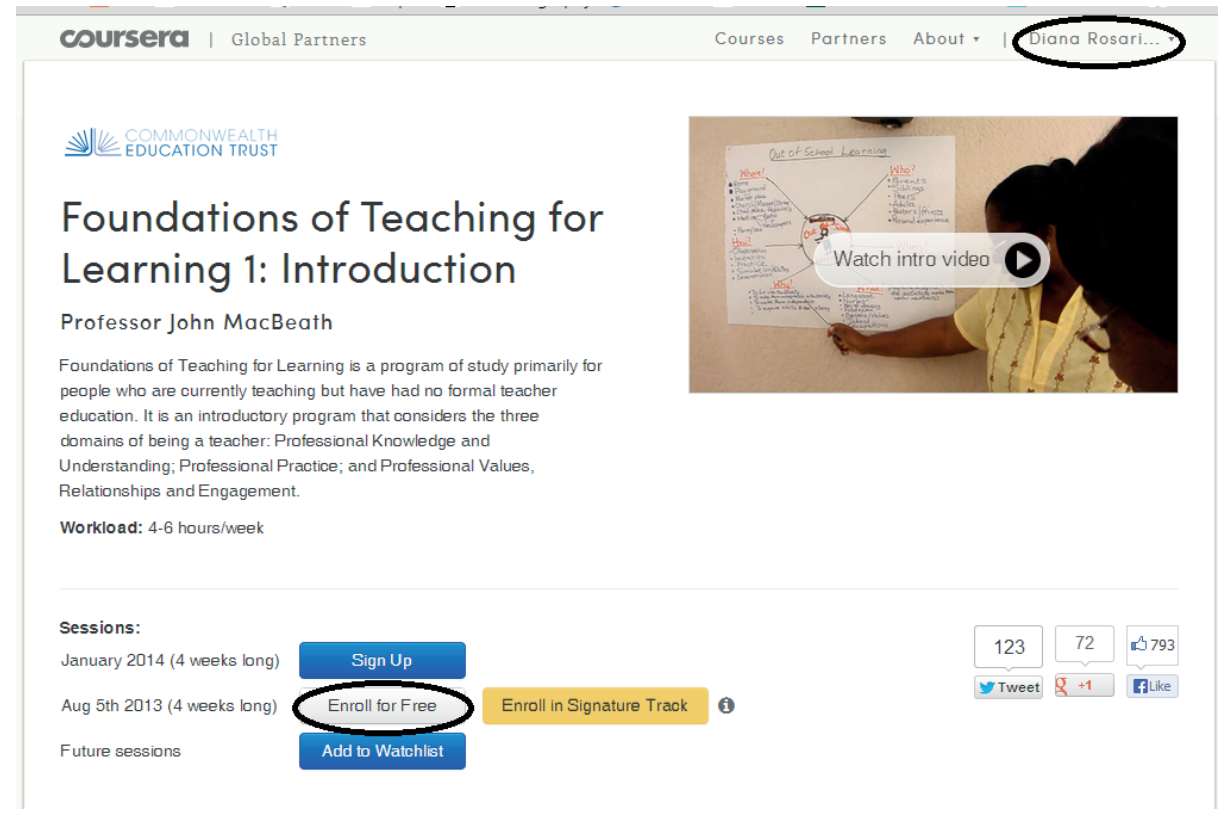

Figure 2.16: First step to enrol for free in the course

\section{Congratulations!}

You're signed up for Foundations of Teaching for Learning 1: Introduction. The course is open and you can start watching lectures and participating on the forums with other students right now!

\section{Go to class}

\section{Earn a Verified Certificate with Signature Track}

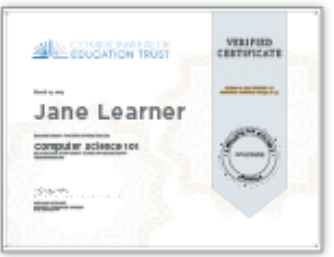

Signature Track enables you to securely link your coursework to your identity, allowing you to confidently show the world what you've achieved on Coursera.

\section{Learn more $n$}

Figure 2.17: Second step to go to class 


\section{Honor Code}

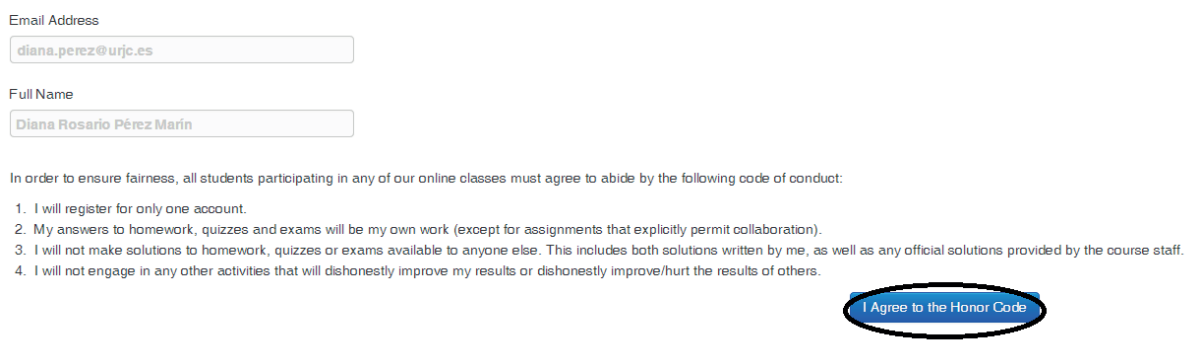

Figure 2.18: Third step to agree to the honour code

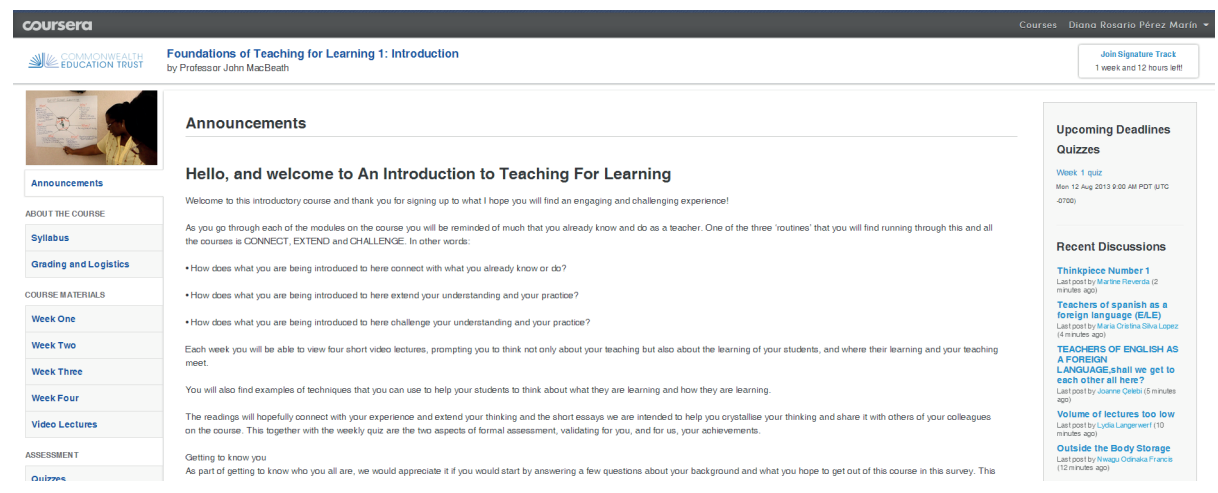

Figure 2.19: Fourth step to read the welcome webpage

Fifth step: Enjoy the course. Now you can read lesson 1, do the quizzes, collaborate with other students in the forum. The course has started and you can fully take part. Level 1 of Bloom is achieved when you learn something about the topic, and level 2 when you understand it, something you can prove when you are able to explain it in other words to your colleagues in a social network, for instance! Figure 2.20 shows you one of the videos in Lecture 2. See what I am learning about the curriculum? While I see this slide, I listen to the teacher, and I can even join a meetup group ${ }^{16}$ with other students to talk about it.

16 A meetup group can be defined as people with similar interests who plan events together and facilitate offline gatherings of the members in several locations. 


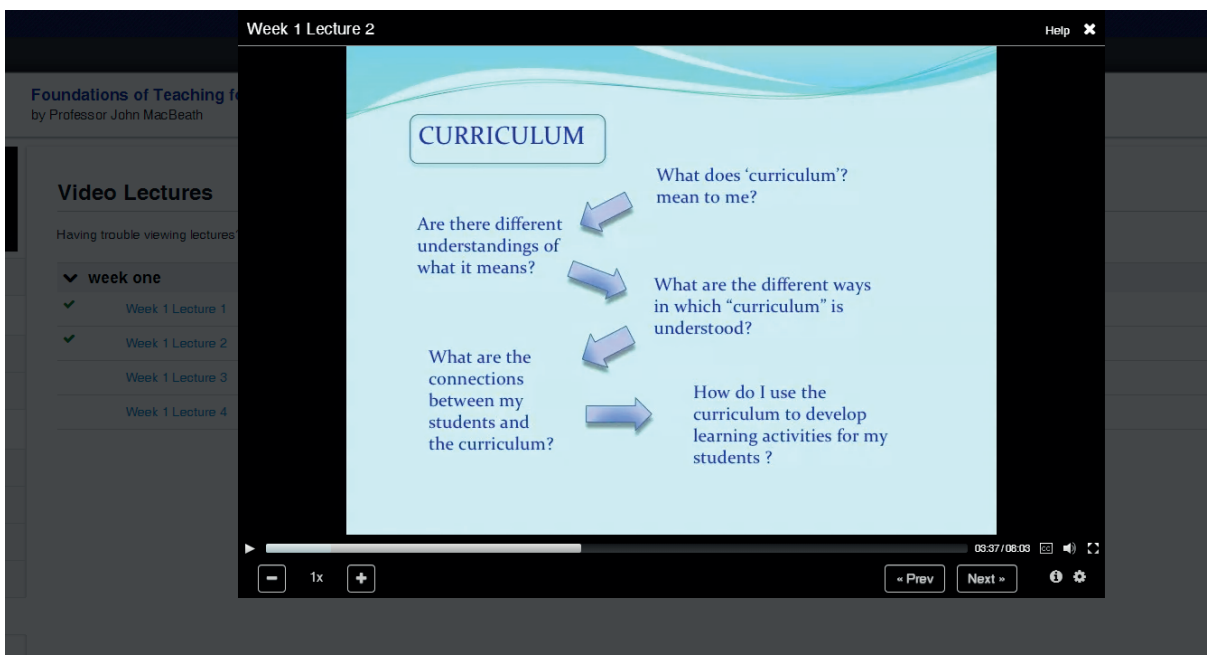

Figure 2.20: Fifth step to enjoy the MOOC: read, listen and share knowledge

\subsection{Google Resources for Education}

Besides education portals and MOOCs, there are other interesting resources to accomplish levels 1 and 2 of Bloom's taxonomy on the Internet. For instance, the resources provided by Google in the pack “Google Apps for Education”. Figure 2.21 shows an image of the available Google Apps for Education.

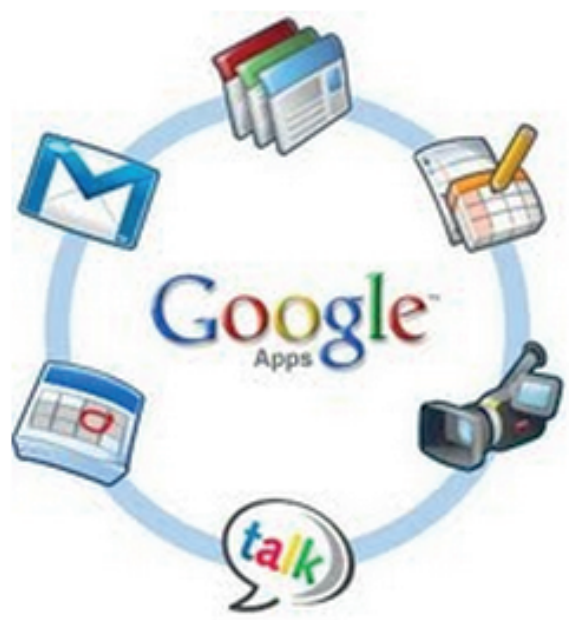

Figure 2.21: Google Apps for education 
There are five apps, namely:

- Gmail: to send and receive mails (up to $25 \mathrm{~Gb}$ mail storage free).

- Google Calendar: to organize your agenda.

- Google Drive (before Docs): to create and share documents, spreadsheets and presentations.

- Google Video: to share video (up to 10Gb free).

- Google Sites: to create websites (up to 100Gb free).

They are all provided free. You access them on-line, they are installed in Google computers, and the only requirement, if you'd like to keep the name of your school or university (i.e. you do not change your account from name.surname@university. es to name.surname@gmail.com), is to provide a domain (ask the IT coordinator in your center). Nevertheless, this is the corporate solution, which can be downloaded from http://www.google.com/apps/intl/en-GB/edu/ just by clicking on the button "Get Apps today" as shown in Figure 2.22. This is the webpage in English, but you can choose any other language by clicking on the pull-down menu on the left of "Sign in".

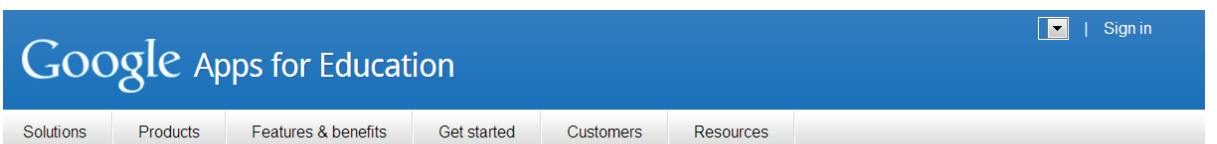

\begin{tabular}{|l|l|l|l|l|l} 
Solutions & Products & Features \& benefits & Get started & Customers & Resources \\
\hline
\end{tabular}

Free email and collaboration tools for schools

Figure 2.22: How to download Google Apps for education

Many universities and schools use Google Apps for Education. For example, it is used at the University of Westminster, Wesleyan University, GeorgeTown University, Unochapecó University, The University of Michigan, Monash University, Northwestern University, Brown University, Vanderbilt University, University of Benin, etc. You can read some testimonies on-line ${ }^{17}$. Nevertheless, a particular institution may not want to use these resources. Does that mean you cannot use them? No, it does not since you can set up an individual Gmail account, and with that account you get access to the rest of the suite. Let's see, step by step, how you can do that, and how it can help you as a teacher.

17 http://www.google.com/intx/es/enterprise/apps/education/customers.html 


\subsubsection{Gmail to Communicate With Students}

First step: to create a Google account, you must fill in the form available on-line ${ }^{18}$ as shown in Figure 2.23. Google will check that your username is not already taken. If so, you will be offered alternatives. Also, it will check that the form is correctly filled in, including your password (a strong password should have at least 8 characters with letters, upper and lower case, symbols and numbers mixed. Do not use common names that appear in a dictionary or family information such as your sister's name, these are not safe passwords!), your mobile phone number and a kaptcha (i.e. an image with letters that you must type to prove that you are not a robot). Remember to read the Google terms, and if you agree with them, tick the checkbox accepting the terms. If everything is correct, when you click on "Next" then you go to a page such as the one shown in Figure 2.24. Finally, to access your account from the webpage in Figure 2.24 you just need to click on the button "Continue to Gmail”, otherwise you are asked to solve the problem until everything is correct and you can access your account.

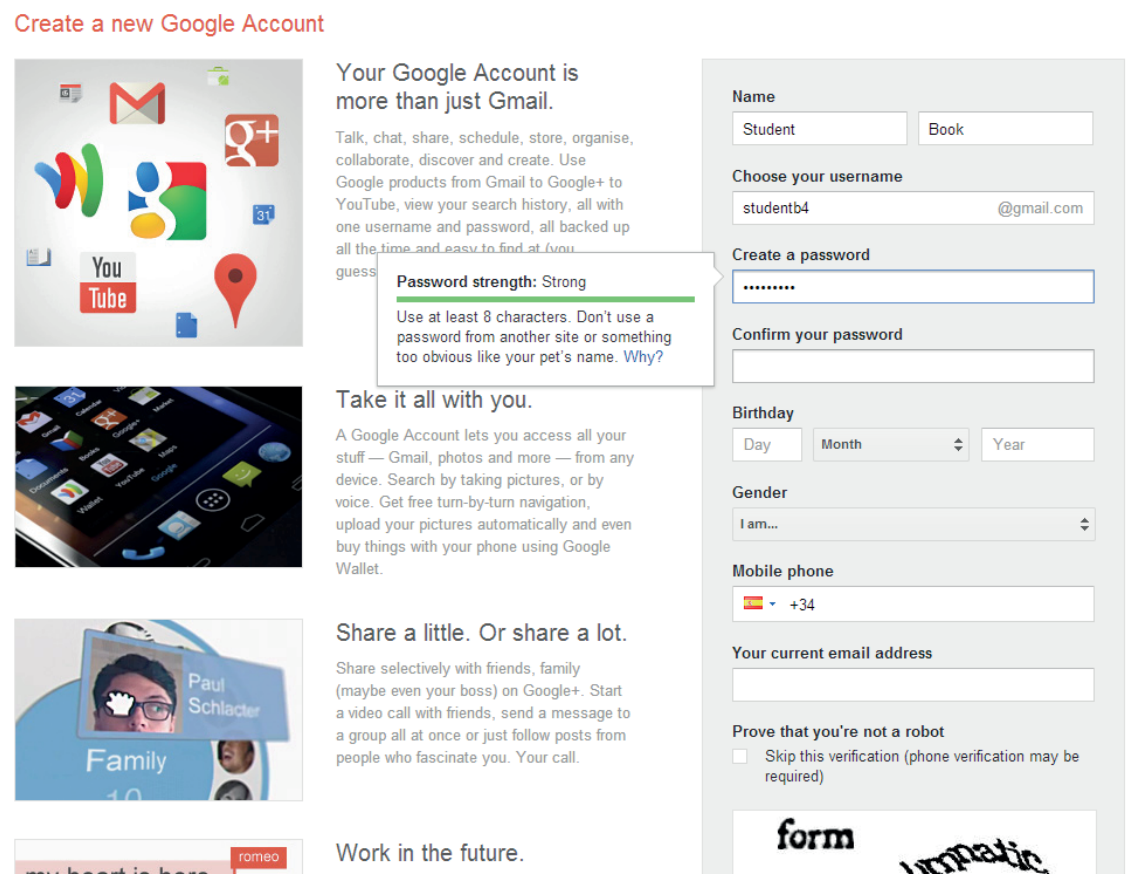

Figure 2.23: How to create a new Google account for free

18 For English users, the link is https://accounts.google.com/SignUp?service=mail\&continue=https $\% 3 \mathrm{~A} \% 2 \mathrm{~F} \% 2 \mathrm{Fmail} . g 0 o g l e . c o m \% 2 \mathrm{Fmail} \% 2 \mathrm{~F} \& \mathrm{ltmpl}=$ default\&lp=1\&hl=en-GB 
Figure 2.24: Confirmation of the creation of the Google account

Second step: to log into your Google account. Just after creating the account, you can see your mailbox as shown in Figure 2.25. There are three welcome e-mails ${ }^{19}$ from the Gmail Team. I advise you to read them because they are useful to learn some tips for using Gmail. You can also follow a quick welcome tour by clicking on the "Next" button in the Welcome pop-up menu. Otherwise, you can click on the upper " $\mathrm{X}$ " of the Welcome pop-up, and come back to the Gmail main webpage.

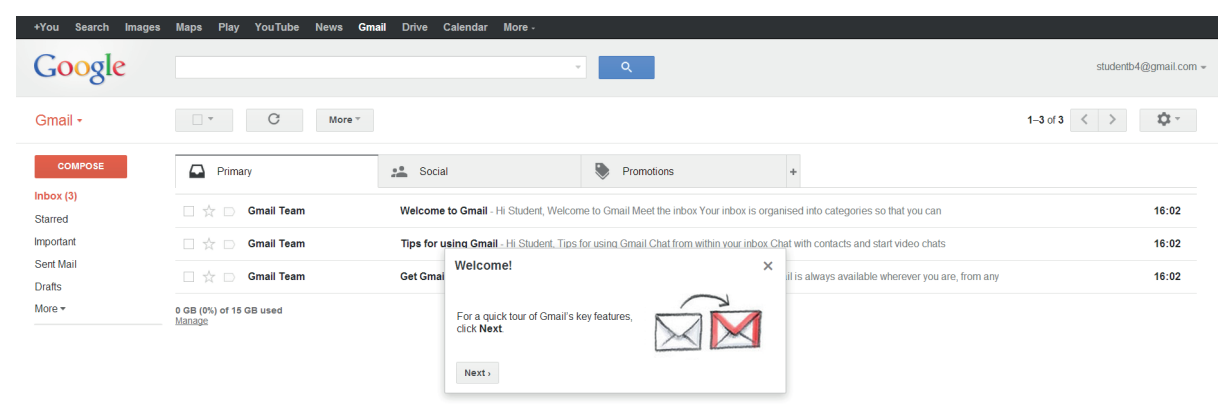

Figure 2.25: A snapshot of Gmail the first time a new user logs into his/her account

Third step: try to sign out and sign in again. OK, but before sending e-mails, just check that you know how to log off and log in (if you know how to do that, you can skip this step). Remember when I told you in the education portals section, that upper right corners were very important for search engines! Yes, very good! In this case, it is also very important, because if you click on your new e-mail account (in our example, studentb4@gmail.com), you find the button “Sign out”. You can see how to do that in Figure 2.26. It is very important that you sign out of your account every time you finish using it. Otherwise, for instance, just closing the webpage, does not guarantee that

19 E-mail is the short for electronic mail. It can also be written as email. In this text, I will always use the term e-mail but please notice, that it is the same. 
you have signed out, and other people may have access to your mailbox, and even send e-mails in your name. Trust me, you do not want that to happen! So, sign out every time you finish working with your account.

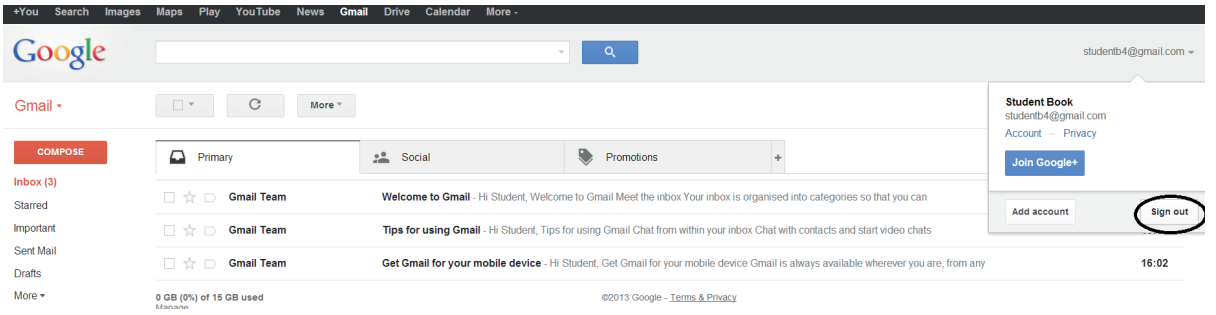

Figure 2.26: How to sign out from Gmail

So, now let's sign in again, we have not finished exploring the possibilities of Gmail! To sign in you must go to the Gmail webpage (you can just type gmail.com in your browser), and then type your user and password as shown in Figure 2.27 and click on the "Sign in" button.

\section{Gmail \\ Experience the ease and simplicity of Gmail, everywhere you go}
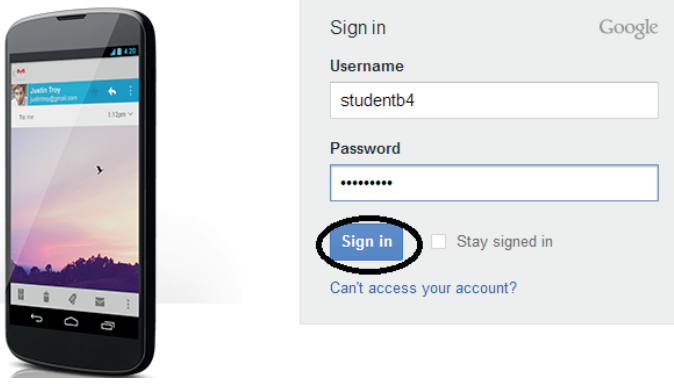

Figure 2.27: How to sign in your Gmail account

Fourth step: read your mail. OK, so we have our account, but how can that help a teacher accomplish levels 1 and 2 of the taxonomy? Well, you can share knowledge with your students by sending them some e-mails with a link to an interesting webpage, for instance. To do that, you need to be able to send e-mails. Moreover, you need to be able to read e-mails. If you already know how to do that, you can skip this step. Otherwise, stick around, because there are three different input mailboxes that I want to present to you: the primary, social and promotions. If you click on the "+” tab right next to "promotions" you can even create your own tabs, if you want to 
organize your mail in other tabs. You can also focus on the "Primary" input box, it is your choice! Anyway, when you see the list of e-mails as shown in Figure 2.26, maybe they are some students' questions. To read them, you just click on the "Subject”, i.e. the title of the e-mail. For instance, in Figure 2.26 for the first e-mail, you will click on "Welcome to Gmail". As you do that, you will see that the webpage changes to show you the content of the e-mail (see Figure 2.28). You can print the e-mail by clicking on the "printer" icon, and you can even answer back by clicking on the "back arrow" (some e-mails indicate that you cannot directly answer them, but it does not usually happen with students).

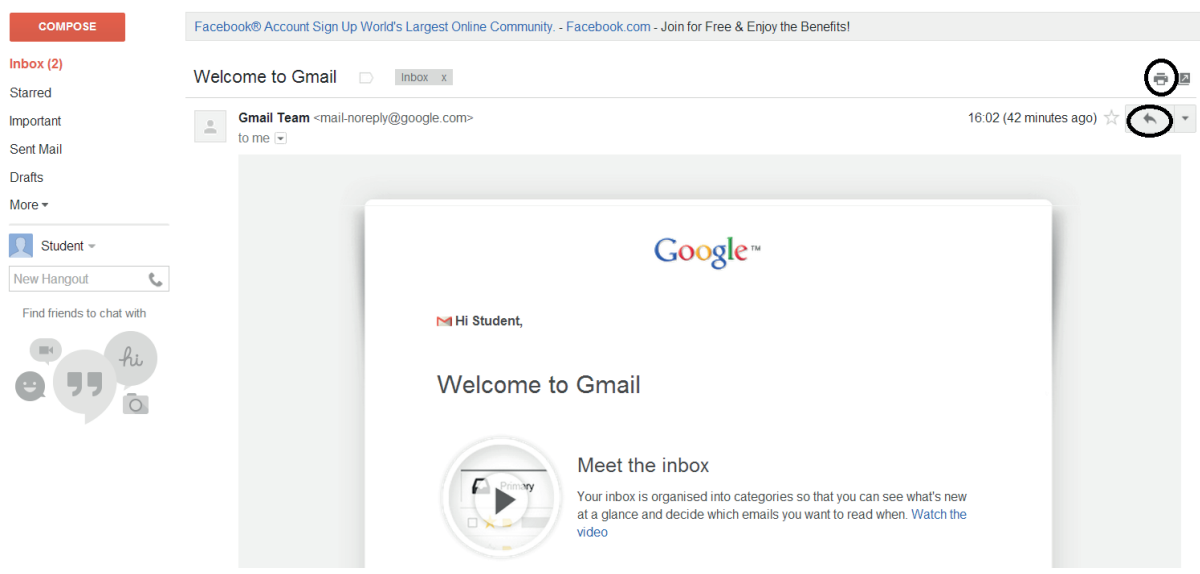

Figure 2.28: Reading a mail in Gmail

Let's play a little game! Find one difference between Figures 2.26 and 2.28....I am not going to tell you the answer....look at the snapshots....look harder!

Have you noticed the difference? If you did not, do not worry, I'll tell you: please, focus on the left column in Figure 2.26 below the "Compose" button, and next to the "Inbox" word, there is the number 3, what do you think that this 3 number means? It means that you have 3 e-mails that you have not read. If you now look at Figure 2.28, we have already read one e-mail, so the number has decreased to 2 e-mails, and when you read all your e-mail, there is no number, until you receive a new e-mail.

Fifth step: compose e-mails. You just read that a student has a doubt regarding one of the topics taught today in class, what can you do? You could just make the student wait until the next face-to-face class, or you can answer his or her e-mail. Do you know already one way to do that? You may recall that I have just told you that when you are reading e-mails, as shown in Figure 2.28, if you click on the back arrow then you can 
answer them. So, let's click on the back arrow to see what happens. Again, if you already know how to compose mails, you can skip this step. Otherwise, please have a look at Figure 2.29, there is now a big text area, in which you can write your answer, and click on "Send" when it is ready. You can also discard the message by clicking on the basket. Next to the basket, there is a little triangle, in case you want to choose another option, such as print the answer, check its spelling or change the composition interface. One interesting feature of Gmail is that if the student answers back, Gmail will join all the messages together as a conversation by default, so that you can read all of them in sequence.

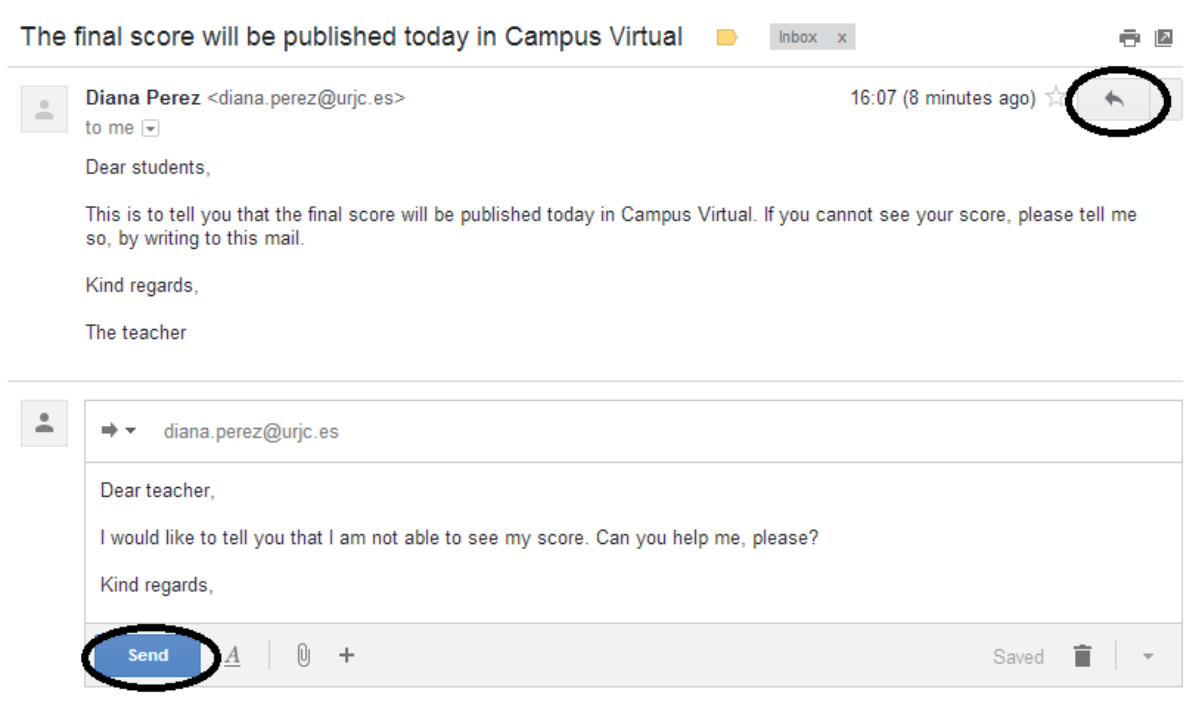

Figure 2.29: Answer back a mail in Gmail

Ah...but maybe you just want to remind your students to bring their calculators for tomorrow's class. You could phone them, but it would take you a long time...why don't you send them an e-mail? In this case, you are going to use the "Compose" button that you can see in Figure 2.29 on the upper left corner. So, let's click on the "Compose" button, and write our first e-mail to the class as shown in Figure 2.30. When clicking on the "To", we must write the e-mail addresses of the students we want to e-mail. If the e-mail is for a small group of students, we can write several e-mail addresses separated by commas, than we can choose from the contact list (each time a student writes to us, his or her address is saved in the contact list). If you do not want the addresses to be shown, then click on "BCC". Also, if you want to create a group, you can select all the e-mail addresses and give them a name. 
myclass@gmail.com

Bring your calculators for tomorrow Math class

Dear students,

I would like to remind you all that for tomorrow Math class it is compulsory to bring your calculator. Do not forget them at home!

Kind regards,

Your teacher

\section{Send}

Figure 2.30: Compose a mail in Gmail

The next line is for the "Subject", i.e. the title of the e-mail, in this case "Bring your calculators for tomorrow Math class". It must be short and direct. It should tell the person who receives the e-mail the general idea of the e-mail. Finally, the third text area is for the message. It usually starts with some greeting, and several paragraphs with the information you want to send. The information is not necessarily limited to plain text information. If you click on underlined "A" at the bottom of the composition page, you can change the format (italics, bold, etc.), font color, background color, etc. providing additional style features to the mail. Moreover, if you click on the "clip" icon, you can attach some files, from your computer or Google Drive (we will see more about that later in this Section).

I would also like you to pay attention to the "Saved" word on the lower right corner. It is important because when you are writing an e-mail, it is being saved as a draft. It means you can sign out of Gmail, and by clicking on the "Draft" option of the left menu, you can resume editing the mail later. As before, by clicking on the basket you can.....yes, discard the message! And, the little triangle gives you more options such as printing the e-mail or checking the spelling.

\subsubsection{Google Drive to Create and Share New Resources On-line}

Let's look again to Figure 2.25, because once we created our Gmail account, we were not only given the option of sending mails (there are many tools to read and send e-mails on the Internet), but look at the upper menu in black. Next to the "Gmail" word that appears in white because it is the app that we are currently using, there is "Drive". Google Drive is the Google app to create and share resources on-line. You can 
create documents, spreadsheets, presentations and even forms on-line. It is a really useful and powerful tool for any teacher, so please read carefully this section and try every step if you have not already used Google Drive. Figure 2.31 shows a snapshot of the welcome page of Google Drive. As you can see, now the word in white in the upper black menu is Drive because it is the app that we are currently using. You can also download a version for your PC, or just use it on-line.

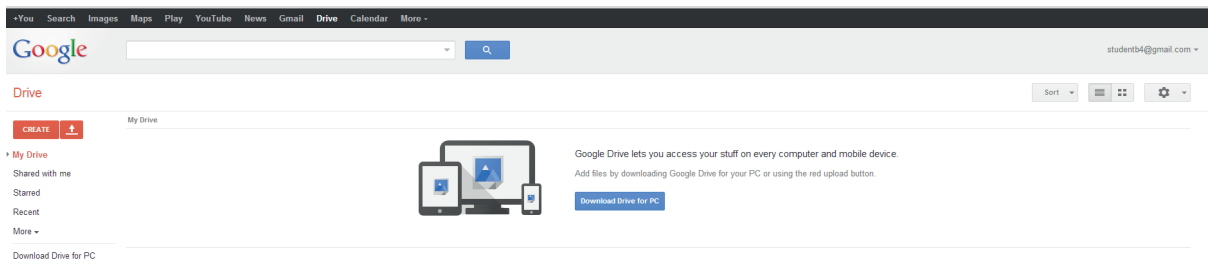

Figure 2.31: Snapshot of the welcome page of Google Drive

OK, let's create our first education resource in Google Drive: a document. To do that, first of all, it is necessary to click on the "Create" button, and choose from the list the option "Document”. Once you click, you will see a page similar to the one shown in Figure 2.32.

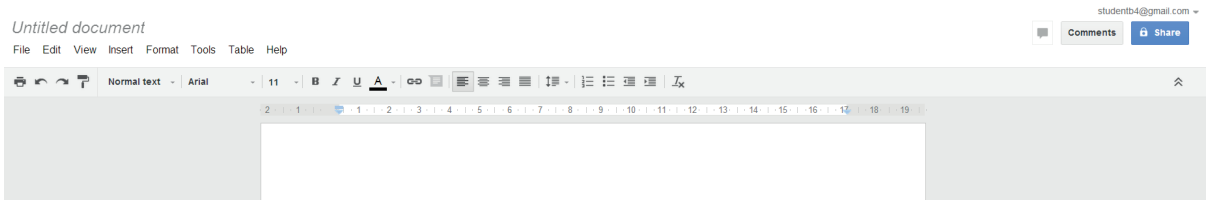

Figure 2.32: Creating a document in Google Drive

It seems like a Word processor, because it is a Word processor, with one important difference, when you save a document here, you are saving it on-line. This means you can access this document from any computer just by signing in with your account. Moreover, you can share this document, and even edit it collaboratively (each person has a color). It is really useful to work in groups, without fear of losing some previous version because Google Drive saves a history of changes. The only disadvantage my students have found when using Google Drive to create documents in groups is that sometimes when you download the final document, some format options are lost, and you need to edit it again in a local Word processor, but the content remains.

OK, so let's learn how to use this on-line Word processor that Google Drive offers to us. The first step is to know how to write, this one is easy: you click with the mouse on the white text area and you can start typing! What happens if you want 
to change the format? You click on the option you want to change. For instance, the font type, it is by default Arial, but if you click on "Arial" you can choose another font, just by clicking on its name. Similarly, if you want to change the font size, you just need to click on the number. By default, it is 11. For other options, like bold or italics, you just click on the icon to activate it, and click again to turn it off. If you want just to put a word in bold, you just select this word. Otherwise, everything you start writing will be in bold, if you did not select anything and you clicked on the icon to select bold. To learn more about Word processors, you can read books such as Yilmaz (2013) or Holzner \& Holzner (2009).

Is the document being saved? Look right next to the menu, after the word "Help" when you make some changes, Google automatically saves them and shows a sentence like "All changes saved in Drive". You can also change the title of the document so that it is no longer "Untitled document", just by clicking on the title. Let's change it to "My first document in Google Drive”. Let's insert a table by clicking “Table” on the menu bar, and choosing the number of columns and rows. Let's insert an image too, by clicking "Insert" on the menu bar $\rightarrow$ "Image" and upload a file from the desktop (take care that you have the rights to upload that image!). See Figure 2.33 with the changes.

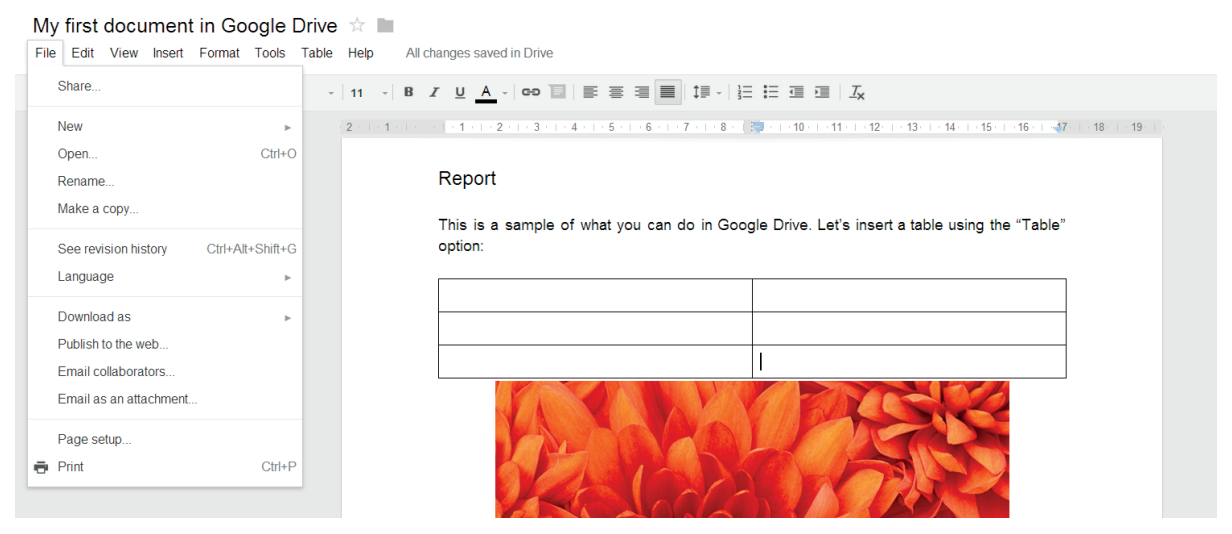

Figure 2.33: Sample document in Google Drive with a table and an image

As you can see in Figure 2.33, the "File" menu is very powerful in this app. You can download the document to your computer with the option "Download as" PDF,. docx, webpage, etc. You can publish the document on the web, see the revision history, rename it, print it, and even share it. Let's focus on the sharing option. Until now, we have been the only editors of the document, but one of the advantages that the document is on-line is that we can work collaboratively with other people. So, let's click on “Share...”. A page like the one shown in Figure 2.34 appears, asking you whether you would like to share the document with some collaborators in a social network (Facebook, Twitter,...) or you would like to share the document with some 
collaborators by inviting them via mail. Anyway, Google Drive gives you the link that they need to access the document on-line, and it tells you that you are the owner, and the rest of the collaborators will have the rights that you give them (e.g. access to view or edit your document). When you have finished changing the options, you just need to click on the buttons "Done" and "Share to mail".
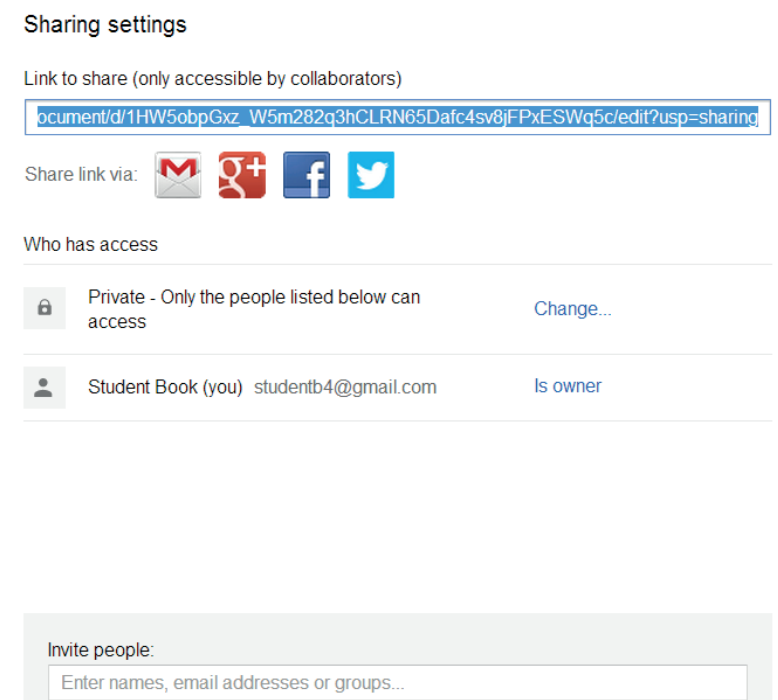

Figure 2.34: Sharing settings in Google Drive 
For instance, I sent an e-mail to my collaborator Iván with the link to the document, so that he helps me with the document. I also chose that "anyone with the link" can view the document, and later I changed "can view" to "can edit” so that Iván cannot only view the document but edit it. When he reads the e-mail (see Figure 2.35), he has the link to view and edit the document.

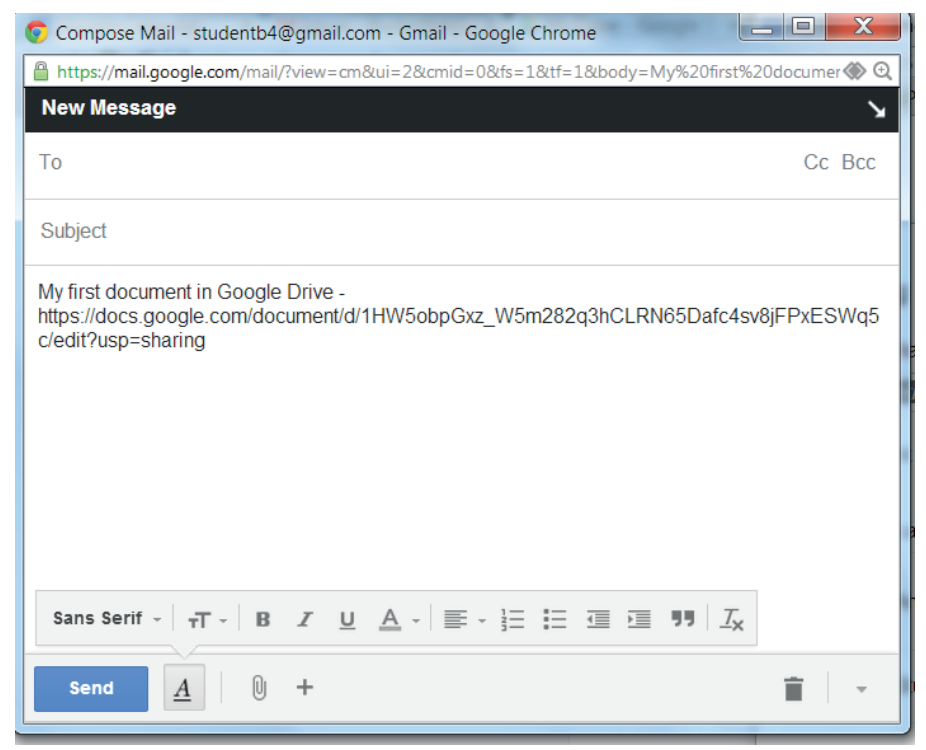

Figure 2.35: Mail with the link to invite a collaborator to work with me in Google Drive

We can also talk by Google Talk, as I have placed him in the list of contacts to chat (in Gmail on the left lower corner). So, we can see when we are connected with a green circle. If I want to chat, I just need to click on the name, and a page as the one shown in Figure 2.36 appears. If you want to write something, you just need to type in the text area below and press the "Intro" key. The message will automatically appear on the dialogue. If the other person has an "orange" circle, you will not get an answer, because it means that $\mathrm{s} /$ he is not connected.

Nevertheless, your message has been sent, and when s/he connects to the chat, $\mathrm{s} /$ he will be able to see it and answer. On the other hand, if the other person has a green circle, s/he can answer you back immediately. Iván was connected, so he could answer my message, and we talked about doing the report together (the one that I sent the link to by mail, I also copied the mail in the chat dialogue) in Google Docs (you will see that sometimes people still use the name Google Docs, because it was its name before it was called Google Drive). 


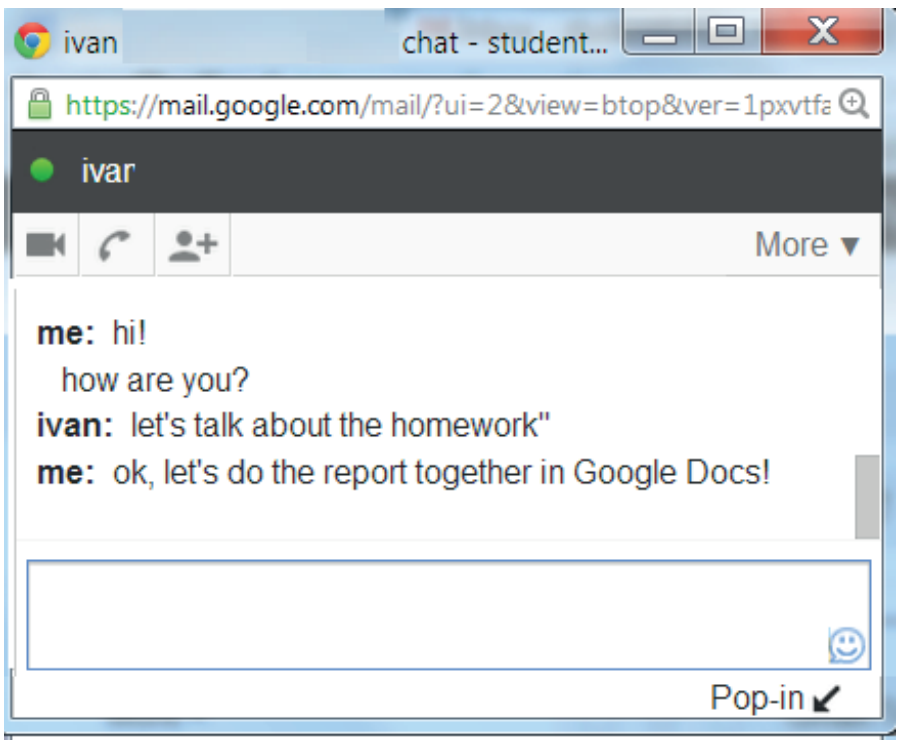

Figure 2.36: Sample chat between students using Google Drive

Now, it's Ivan (his cursor is pink) the one that is writing on the document as can be seen in Figure 2.37, and I can see immediately the changes made, as they are being saved. By clicking on the "See revision history", I can also restore any previous version, just by clicking on its name and next "Restore this revision". That way, you should not be afraid of losing any information (something that can be really scary when you are working collaboratively!).

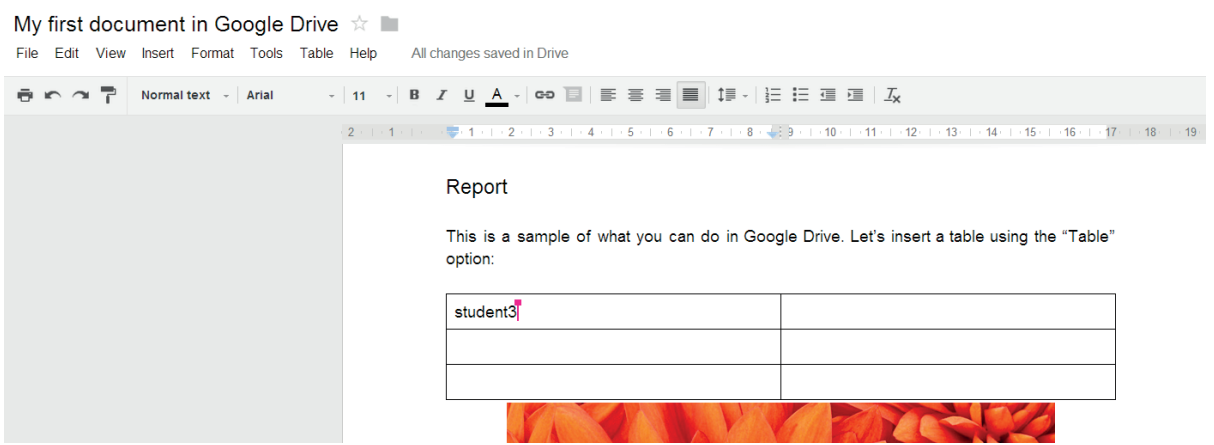

Figure 2.37: Collaborative edition of a document in Google Drive 
If we have finished working with the document for today, we can close the browser tab of the document, and go back to the main page of Google Drive as shown in Figure 2.38. You can see how the document is already saved in the list of documents uploaded on the Internet. This is an example of a document you have created from scratch, but sometimes, you may want to upload something you have in your computer, for instance, a test, to share with other teachers to review it before printing, so that all teachers of the course have the same test.

How can you upload it? Well, you can see in Figure 2.38 the button with the arrow in red, just right next to "Create", it means that you can upload a new file or folder to Google Drive (and you and the people you invite will have access from any device connected to the Internet). The next document will appear in the list just above our previous document, and you can access either of them, just by clicking on their name. It is time you practised that! Have you finished? Are you sure? Can you tell me what happens if you click with the right button on one of the documents in the list? Yes, a pull-down menu appears with many possibilities! For instance, you can remove the document from Google Drive, download it, make a copy, etc.

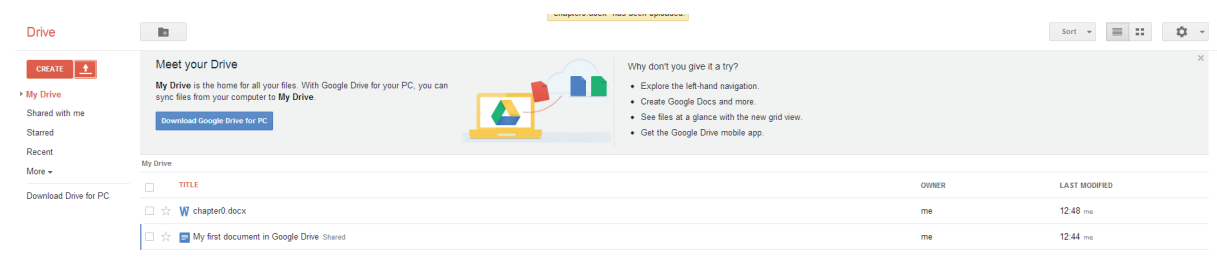

Figure 2.38: List of documents uploaded in Google Drive

OK, so you have already learnt how to create, share and upload documents in Google Drive. This is very good, but sometimes you do not want to work with documents, but you want to create a presentation, spreadsheet or a form. So, let's practise with them! Let's start with a presentation.

By now, you should know, which button should I click on from Figure 2.38? I'll wait for your answer...I am not telling you....well, I will tell you, oh...wait! You remember! Very well, it is the "Create button" (it is always the Create button in Google Drive). It was easy! Wasn't it? And now, you just click on “Presentation”. See Figure 2.38, it looks like a program to create presentations, well it is!

The first step, as you can see in Figure 2.39 is to choose a theme. This will be the background of your presentation. A little advice here: if you like the font in a light color, the background should be dark to contrast. Otherwise, if you like the font in a dark color, the background should have a light color! This time, just for the sake of the sample, let's choose something clear to write in black. To do that, you just click on the theme you like, and click the "OK” button. 


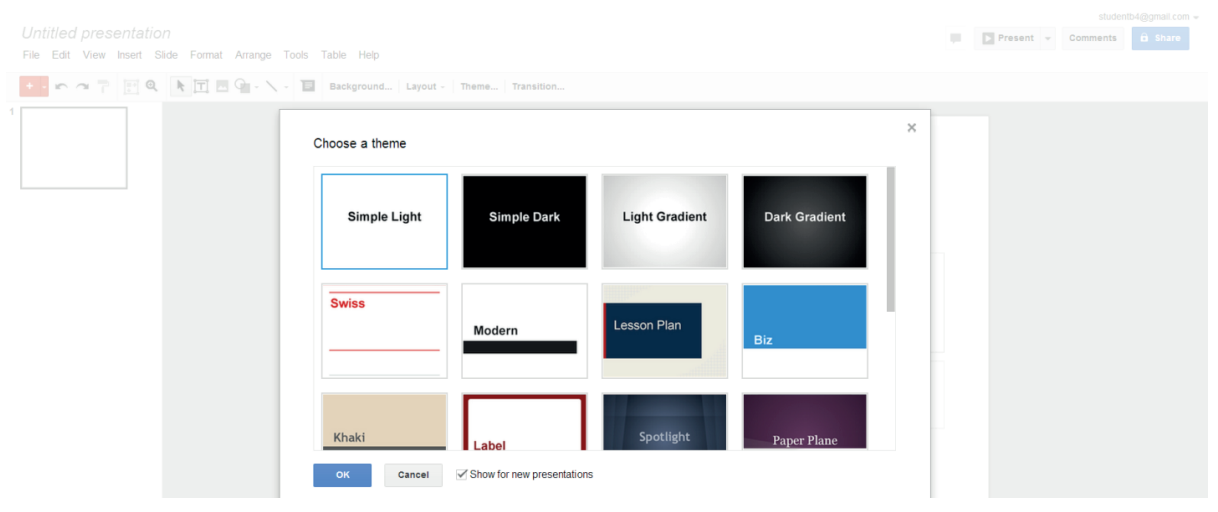

Figure 2.39: Sample new presentation in Google Drive

As you can see, please do the steps with me, with your computer or any device, remember this book is not a novel, you are not going to learn just by reading! So, I assume you already have your presentation in front of you with an untitled name. That's not right. Let's change the name to "My first presentation in Google Drive". This time I am not going to tell you the answer, so if you do not remember how to do that, I would just give you a clue, it is exactly the same as what we did to change the name of the sample document. It is some pages back, read it if you do not remember, and do not continue until you change the name of the document, you do not want to have thousands of untitled documents in your Google Drive.

You did it! I knew you could! Perfect! Let's continue then! We can modify the title of the slide, just by clicking on "Click to add a title". What about inserting a new slide? See the "+" red icon, click there! You have it! Now you have two slides. You can have as many slides as you need, just by clicking on the "+" icon. To edit a slide is pretty simple. You can follow the same advice I gave you for Google Documents, to change the font type, size, bold, etc. You can also insert tables and figures as we did, and invite some collaborators as we did. This is the amazing thing about using apps from the same company, once you've learnt how to use one, it is easyto learn how to use another. Conceptually, it is not the same to write a report and do a presentation, but from the technical point of view, the process is similar.

Figure 2.40 shows you how I have edited the sample presentation, adding an image. Now I want you to focus on the "Present button". This is new, and very useful! Google Drive allows you to save, edit, share and do presentations! You can present them just by clicking on the button, and the slides will appear in full screen size, one by one. You can use this feature to rehearse your presentation too, and even add notes (they will not appear in presentation mode).

If you want to learn more about creating good presentations, I recommend the book written by Weinschenk (2012) who gives really good advice about how 


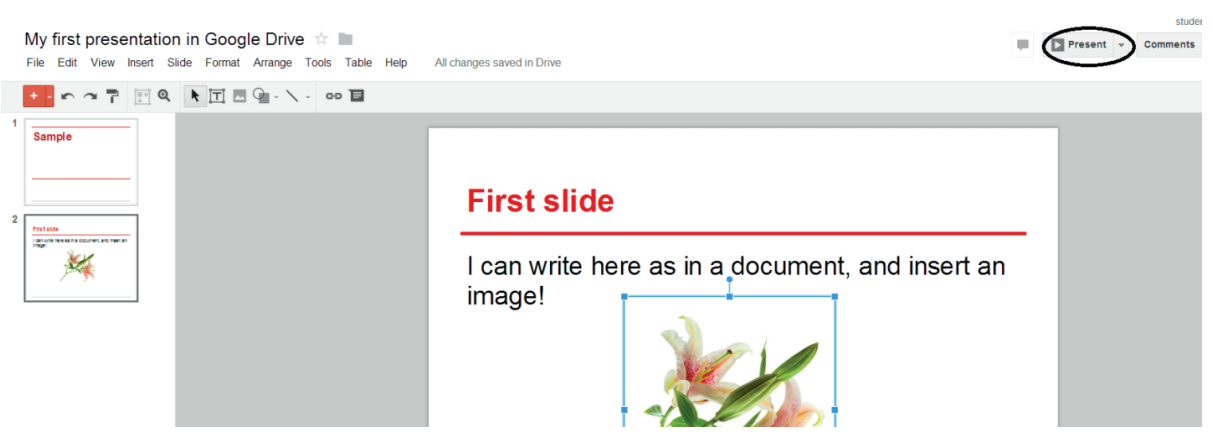

Figure 2.40: Sample new presentation in Google Drive

people think, do not forget that our students are people too! And, from a technical point of view, I recommend the books written by Lamont (2013), and Holzner \& Holzner (2012).

Let's continue with the creation of a spreadsheet. I must confess to you that I love spreadsheets. Why? I love spreadsheets because they have saved me hours calculating the final scores for my students. I just love to add a formula and then automatically, almost by magic, all the students have a score calculated without mistake. There are many more benefits to be gained by using spreadsheets, but I really want you to focus on this aspect, because I have seen, not only in my case, but for other teachers too, how useful it is. I am not going to tell you the first step, because I already told you twice. How can you create something new in Google Drive? Let's go back to the ... button in Figure 2.38, now you should have something like Figure 2.41

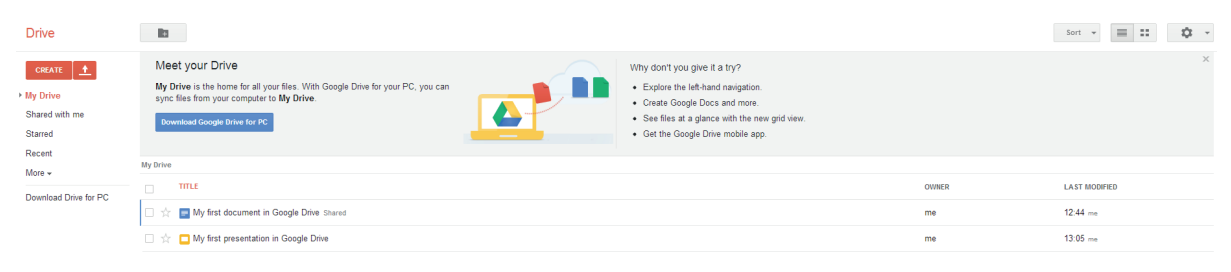

Figure 2.41: Updated list of documents in Google Drive

Have you noticed how each type of document is associated with a different color and icon in the list? It is useful to focus just on documents (blue), presentations (yellow), and other documents (green). So, I assume you already clicked on the red "Create" button, and chose "Spreadsheet". Well done! You are now in a page similar to the image shown in Figure 2.42. 
Figure 2.42: Updated list of documents in Google Drive

As you can see, it looks like any other program to create spreadsheets. You can change the name of the spreadsheet as we already know, and this time, we are going to work with cells. You can move among cells with the arrow keys in the keyboard, with the "Tab" key, or by just clicking on the cell you want to go. You always know which cell you are in because of the letter (for columns) and the number (for rows). In Figure 2.42, which cell was I in? Yes, you did it. I was in A1, very good!

You can also copy information from other spreadsheets, and paste into the cells. I just copied the scores for students A to G in practical work 1 to 4 . Now, I would like to know how to calculate their final score from those scores. The formula is: the final score is the average of the four practical works, so: 0,25 * $\mathrm{P} 1+0,25$ * $\mathrm{P} 2+0,25$ * $\mathrm{P} 3+$ $0,25^{\star} \mathrm{P} 4$. How can you insert this formula in your spreadsheet? You go to the cell in which you want the result to appear. In our first case, the cell is F2. Next, you type the "=" sign. This is very important because that way the program knows you are not typing numbers or text, but a formula. Next, you type the formula, in our case, 0,25 * and here comes the most important part. Remember that I told you how the cells were indicated with the column and row, so how can you tell where the first score is? It is in B2. You can either type B2, or just click on the cell and you can see that you are doing it right because the cell appears with a background color. You can see that in Figure 2.43.

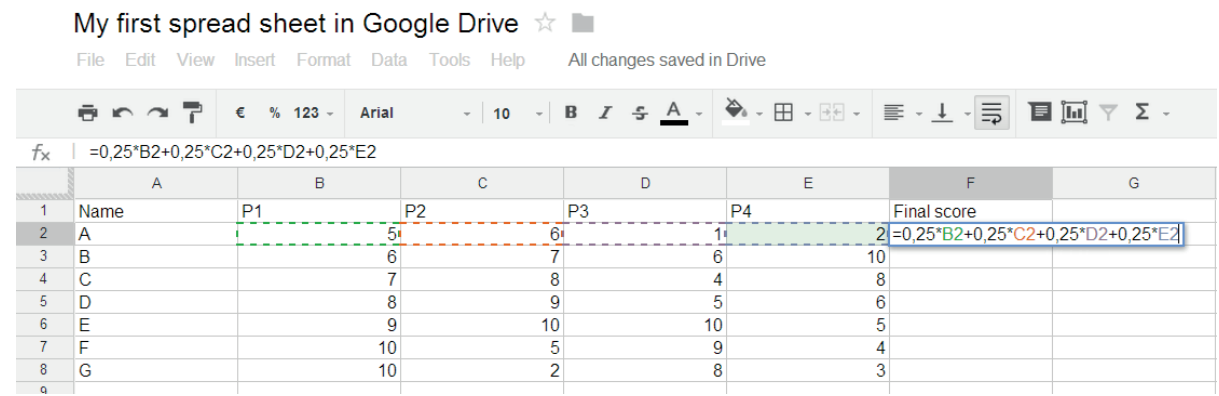

Figure 2.43: Calculating a formula in a spread sheet in Google Drive 
When you type the last "Enter", you can see the result in the cell, and the formula in the "Fx" line. If you want to modify the formula, you need to change it in the "Fx" line. Moreover, if you click on the F2 cell, can you see that the blue border has in the right lower upper corner a little box? It is very important because if you click on it, it changes to a big plus sign and you can, just by keeping the left button of the mouse pressed; go down as many rows as you want, so that when you do not press the left button of the mouse any longer, all the results are calculated! Have you tried it? It is wonderful, this time there were 8 students, but sometimes there are 400 !

There are many books about working with spreadsheets in Google Drive, but given that I already told you some references that are very complete, please just read the chapter on spreadsheets in Lamont (2013), and Holzner \& Holzner (2012). Let's finish for now with a last exercise, a very useful exercise, too, to create a form in Google Drive! But, first of all, what is a form? It is like a paper and pencil form in which you ask people to fill in data, but on-line. Can you imagine the possibilities that this offers to you? You can create surveys to ask about the previous knowledge of your students before attending your course, you can do mock tests so that your students can practise, and the best of all, Google Drive will save the data for you, the people you want to invite, and all of this from any device connected to Internet. Are you motivated to learn how to create a form? I am to teach you! Please, keep reading and keep your computer on! When you click on "Create" -> Form, you go to a page similar to the one shown in Figure 2.44.

As you can see in Figure 2.44, creating and using forms involves four steps: the creation of the form, sharing so that other people can work with you on the form, sending the invitation, and, finally analysing the results in the spreadsheet that Google Drive creates for each form created and saves in the list of documents on Google Drive (see Figure 2.41).

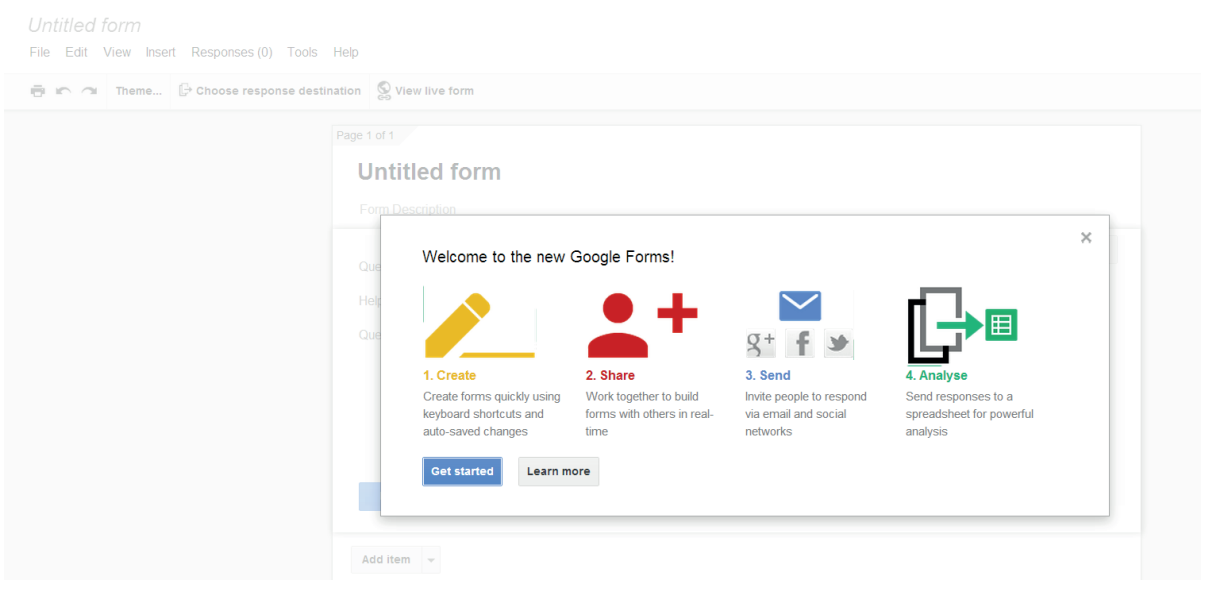

Figure 2.44: Creating a form in Google Drive 
Let's start with the first step and create a form! Figure 2.45 shows the main page to choose the title and theme (like the background of the presentation) for the form. To choose one of them, you just need to click on it, and then click on the "OK" button.

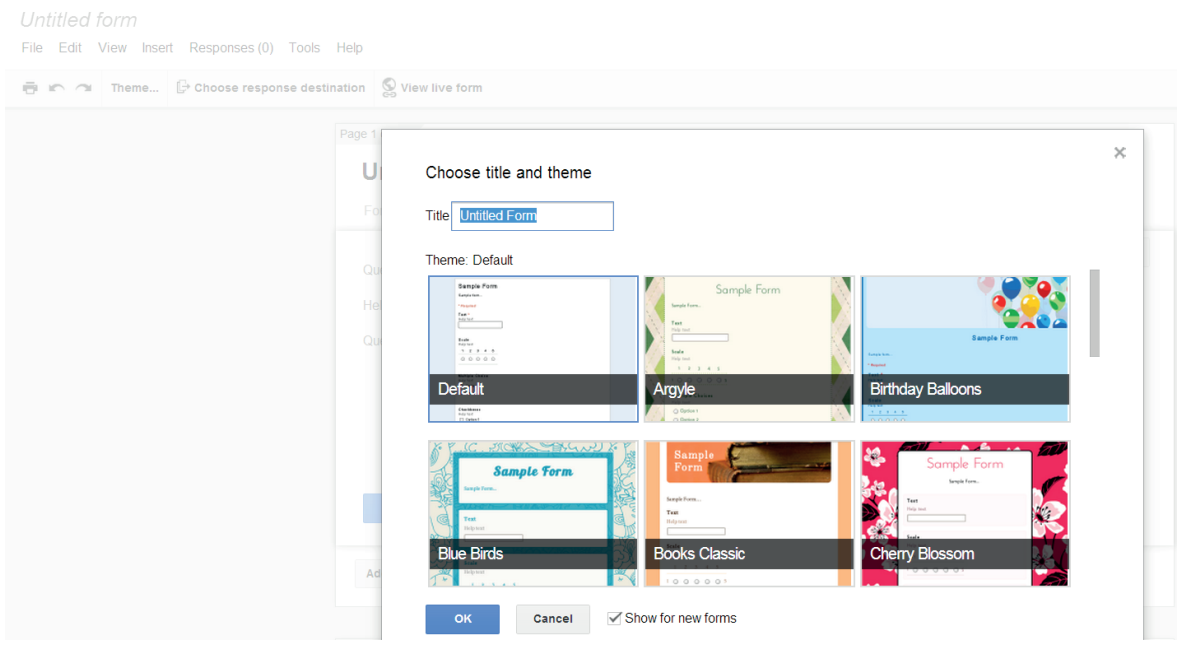

Figure 2.45: Choosing a theme and a title for a form in Google Drive

You can change the chosen theme later by clicking on "Theme", and you can even have a preview of how people will see the form on-line by clicking on the "View live form" button (both of these are in the same row of the format menu in documents or presentations in Google Drive). How long have you been editing the form? 15 seconds, 1 minute? And, see what you have already created in Figure 2.46 after clicking on the "View live form" button.

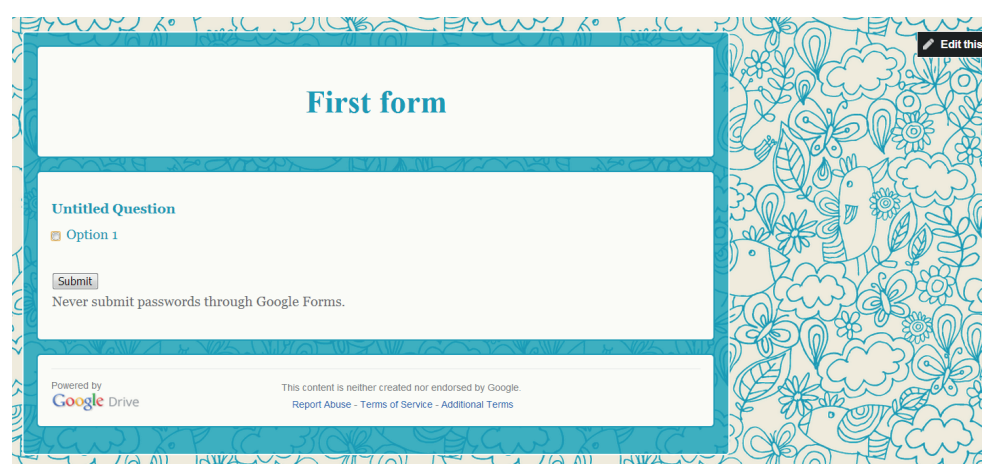

Figure 2.46: Preview of the form in Google Drive 
I can guarantee you, as a Computer Programmer, without Google Drive, creating a form is not so simple. So, let's take advantage of this powerful tool. Let's continue editing the form. To do that, see the black button on the upper right corner, just click on the "Edit this form". To modify something is really intuitive, because what you need to keep in mind is to click on what you need to change! For instance, if I want to modify the form description, I click on it, and I write my own description. Let's change it!

By default, Google Drive provides you with a sample question, if you pass the mouse pointer over the question, you will see that it has a shadow, and three options appear: a pen, two papers and a basket. If you pass the mouse over the pen, you can read "Edit", if you click you can change the question. Sometimes, you want to create a question very similar to some previous question, you can duplicate it by clicking on the two papers icon. Moreover, if you want to remove a question, you just need to click on the basket icon. Let's create our first multiple-choice question, something like:

Do you enjoy learning Maths?
a) Yes
b) Sometimes
c) No

As you see, these are forms, so there is no correct answer. If you want to use the form as a mock test, remember that the test will not be automatically evaluated. There are learning platforms to create tests on-line for free like Moodle ${ }^{20}$, Edmodo ${ }^{21}$ or Testmoz ${ }^{22}$. Figure 2.47 shows the page to create a question in the form.

If you click on "Question type", you can explore many other possibilities for questions. Anytime, you can remove an answer by clicking on the cross at the right. To add a new answer, you just type in a new text area, and before clicking on "Done" remember that if you want the students to have to answer the questions, the option "Required question" must be ticked. You can add many more questions, by clicking on the "Add item" button. Moreover, you can choose, for each question, whether you would like the users of the form to see the results, or whether they can edit their answer after submitting. If you do not tick these options, by default they are not selected. It is now your turn to explore the possibilities of Google Forms, there are many! If you would like more information, a good book is Darbyshire (2010). Well, you will also find useful information in Lamont (2013), and Holzner \& Holzner (2012). Finally, when you click the "Send form" blue button at the end of the form, it gives you the link that you have to send to all of the people you want to have access to the form.

\footnotetext{
20 https://moodle.org/

21 https://www.edmodo.com/

22 https://testmoz.com/
} 


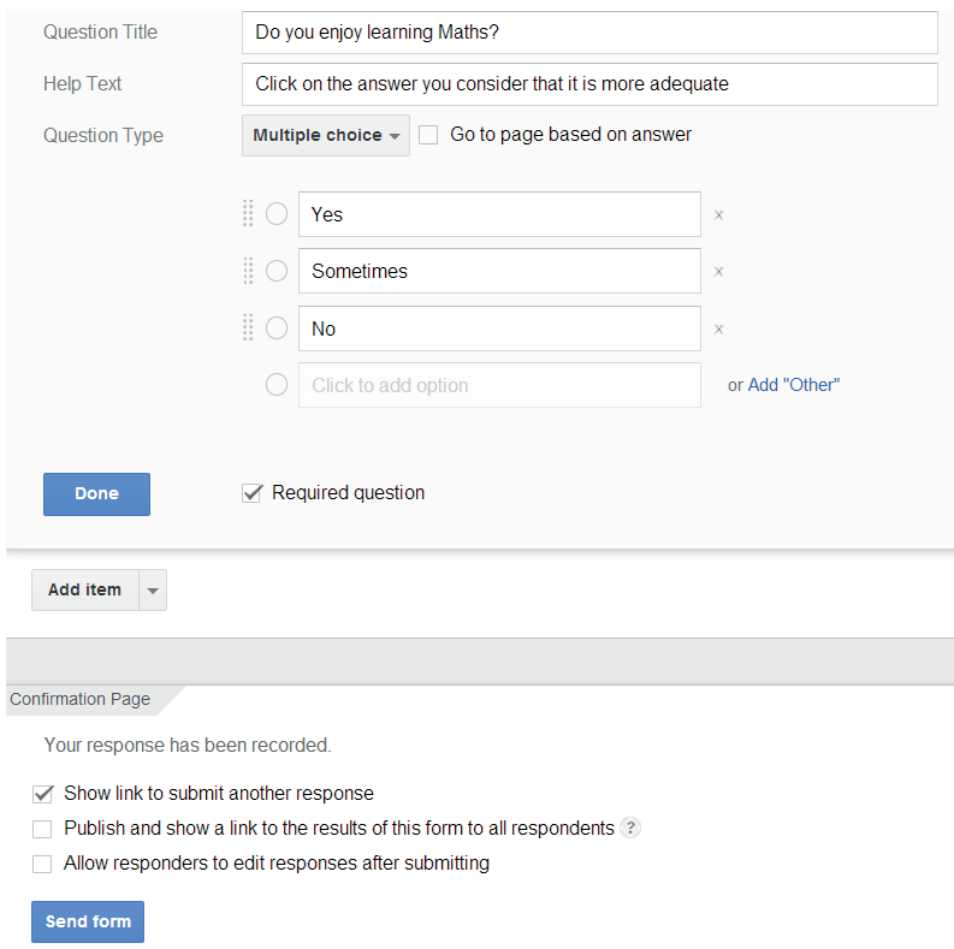

Figure 2.47: How to set up a question in a form in Google Drive

OK, but before sending the link, have you checked the spreadsheet associated to the form? It is always a good idea to test the form yourself first. You can click on the "Choose response destination" button, and type a name for the spreadsheet that will be saved in Google Drive. The name by default is the name of the form followed by "(Responses)". You can see that in Figure 2.48.

When you click on the "Create" button, Google Drive will set up the spreadsheet, and now you are ready to try the link to the form (the one that you see when you go to the live form ${ }^{23}$ ). If you type some answers in the form, you can see how they are saved in the spreadsheet. Try that! By default, the form is "Accepting answers", as you can see in the "Responses" menu. Initially, there is a 0 right next to "Responses". It is because nobody has uploaded any answers. For each user that fills in the form, a row is created in the associated spreadsheet and the number next to "Responses" is increased by one. So, you can now check how the responses are being saved until the date on which you do not want to accept more responses. To stop accepting new

23 My simple form is on-line at https://docs.google.com/forms/d/1a2Y5aPq8t1gDAfMm3FpnOEsajf4 IZgto_EBWvhcBmYA/viewform 
answers, you just need to go to the "Responses" menu and tick the option "Accepting answers" off. See Figure 2.49 for a view of the spreadsheet with the answers. You can even see some statistics, by clicking on "Responses" $\rightarrow$ Summary of responses.

\section{Choose response destination}

\section{- New spreadsheet}

First form (Responses)

New sheet in an existing spreadsheet...

Always create a new spreadsheet ?

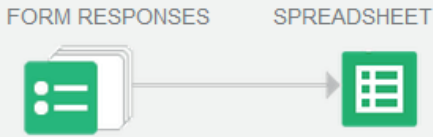

Modify, re-arrange and analyse without affecting original form responses.

Figure 2.48: How to choose a response destination for your form in Google Drive

\begin{tabular}{|c|c|c|}
\hline A & B & c \\
\hline Marca temporal & $\begin{array}{c}\text { Do you enjoy } \\
\text { learning Maths? }\end{array}$ & $\begin{array}{c}\text { What do you think } \\
\text { about } \\
\text { Trigonometry? }\end{array}$ \\
\hline $7 / 08 / 2013$ 17:33:21 & Yes & It is very interesting. \\
\hline $7 / 08 / 2013$ 17:34:41 & Sometimes & I do not know \\
\hline $7 / 08 / 2013$ 17:41:23 & Yes & I like it. \\
\hline $7 / 08 / 2013$ 17:42:04 & Sometimes & I do not know. \\
\hline $7 / 08 / 201317: 45: 18$ & No & I do not know. \\
\hline
\end{tabular}

Figure 2.49: Answers saved in Google Drive for the form

\subsubsection{Google Calendar to Organize Your Class Events}

If we go back to Figure 2.31, we can see how in the upper menu, next to "Drive" there was the word "Calendar". Let's learn more about how using the Calendar can be helpful for teachers. If we click on "Calendar" we go to a page similar to the one shown in Figure 2.50. 


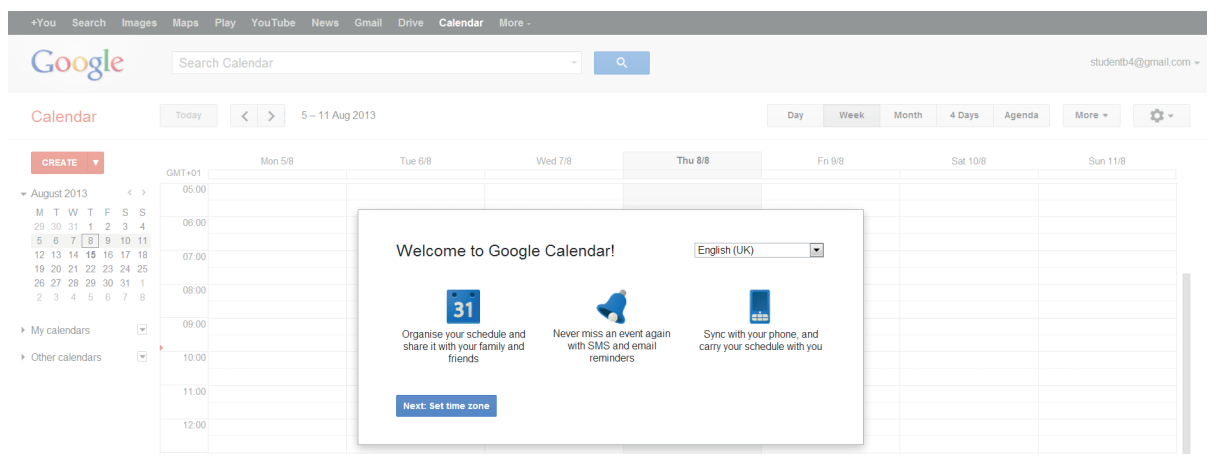

Figure 2.50: A snapshot of Google Calendar

As you can see, it is an electronic agenda. It allows you to organise your schedule and events in the school or elsewhere (you can assign a color to each event to differentiate them). You can even synchronize the information in the agenda to your mobile phone so that it warns you when some deadline is approaching. Google Calendar do not charge you for sending the message to your mobile phone, but your mobile service provider might do, so please check before configuring the alerts. Moreover, a little piece of advice from the experience, do not set up too many alarms. When you have too many alarms you start ignoring them all! Just focus on the real important meetings and events that you cannot afford to miss.

OK, but how can I add an event? This question has a simple answer! You just click on the day and time in which the event is, and a menu similar to the one shown in Figure 2.51 appears. The basic information that Google Calendar needs about the event is the date, time, and a small description. You can type that description in the "What" field. For instance, you can type "understanding test". Once you click on "Create event", it is done. You can undo it by clicking on the upper yellow menu "Undo". You can also edit the event, just by clicking on it. Figure 2.52 shows the possibilities.

As you can see in Figure 2.52, you can modify the title of the event, time, date, description, color, reminders and privacy. The general method to change anything is just to click on it. For instance, if you want to write a description, you just go to the text area and you can start typing. In addition, if you want to change the color, you just need to click on the color and it is changed. Similarly, given that you can share the calendar (as you could share any other Google resource such as a document or a presentation), you can show other people that you are busy at that time, and choose whether an event is public and everyone can see it, or make it private so that other people cannot see it. You can also discard any change by clicking on "Discard changes", and even delete the event by clicking on the "Delete" button.

Google are working now on improving this app by allowing you to add attachments to the events. I have never added an attachment to the event. For me, it is just useful that it reminds me on-line, say 10 minutes before an event and I can have a look at my 
shared calendar with the rest of my colleagues, but adding attachments could be an interesting feature for the future ${ }^{24}$.

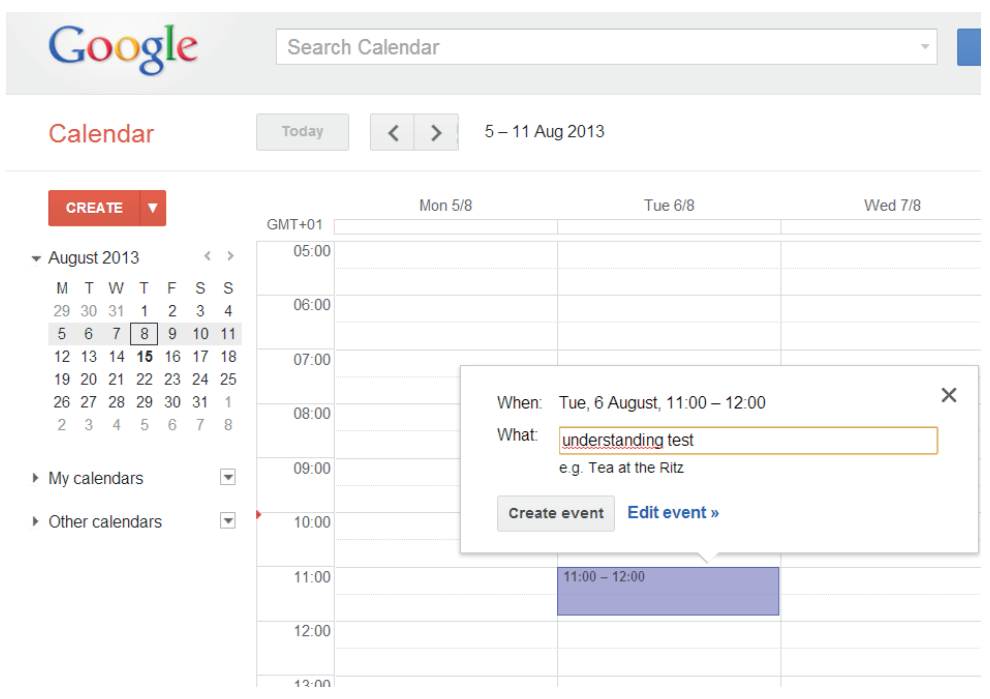

Figure 2.51: Creating an event in Google Calendar

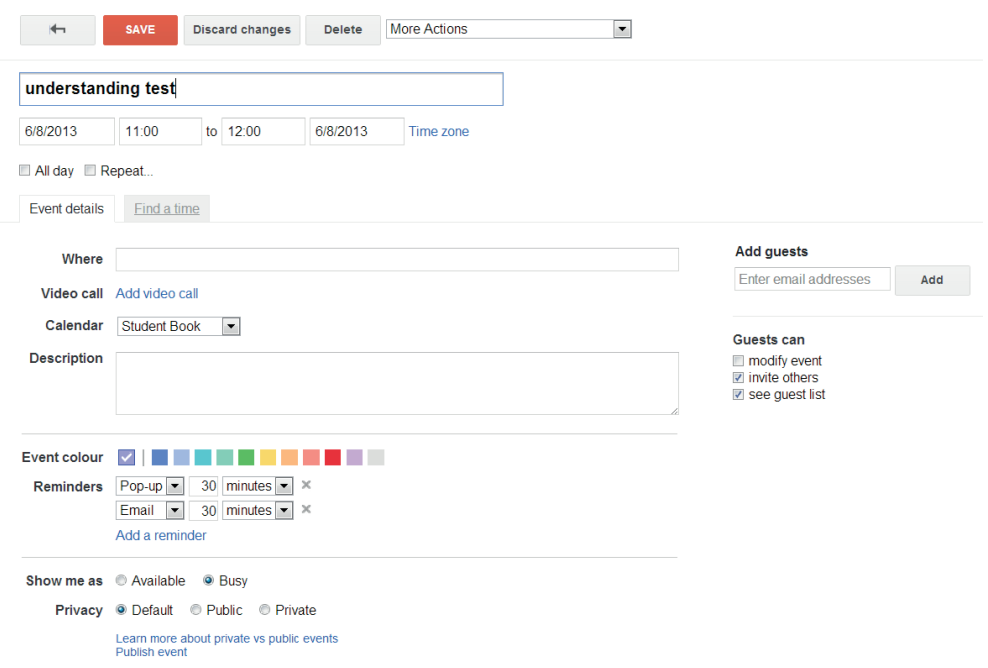

Figure 2.52: Editing an event in Google Calendar

24 New lab features that Google people are exploring: https://support.google.com/calendar/ answer/154174?hl=en-GB 


\subsubsection{Google Video to Find Videos and Google Book to Find Books}

Let's review, we have been exploring in this chapter: options to find resources for level 1 and 2 in Blooms' taxonomy, i.e. to learn and understand new knowledge, and we have found education portals, MOOCs and many Google Apps for education to create materials such as documents, presentations, spreadsheets, and forms. Is it possible to search for resources in Google? Yes, of course, it is! We can use Google Video to find videos, and Google Books to find books. Let's look at these two possibilities.

If we go back to Figure 2.31, we can see how in the upper menu, next to "Calendar" there was the word "More". If we click on "More", we can see that one of the options is "Videos". Have you seen it? Good! We are just about to click on it, and we should go then to a page similar to the one shown in Figure 2.53.
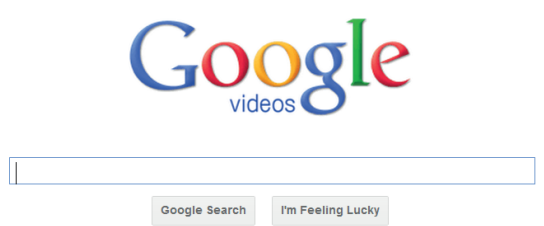

Figure 2.53: Using Google Videos for education

Pretty simple page! That is a really wonderful thing about Google; powerful applications with simple interfaces. Do you know the difference between the "Google Search" and "I'm Feeling Lucky"? If you try writing something, and click on "I'm Feeling Lucky" you see that you go directly to a page. It is the first page in the results of the search, and if you are lucky it contains the answer to your question! Otherwise, if you click on "Google Search" you go to the results page with all the links to the videos that match the keywords typed in the text area. OK, so let's find a video about the Second World War. Let's type in the text area "Second World War", click on "Google Search" and see what happens! Figure 2.54 shows the results page.

I have just clicked on the first link. This is why it is in a different color. I have seen that it gathers several interesting videos that I could play in class to discuss them with my students, so that they learn something more about what happened, and they can accomplish my learning goals in levels 1 and 2 of Bloom's taxonomy. You can also see that there are many links to YouTube, which is a Google resource too, and as I've said before in this book, a really useful tool for the teacher along with the other possibilities we explored in the exercises of Chapter 1.

What happens if I want my students to read more about the topic? Well, it is also possible to search for books in Google. Let's go back to the page in Figure 2.31, and click on "More" $\rightarrow$ "Books". If we do that, we see a page similar to the one shown in 
Figure 2.55. As you can see, Google remembers the keyword I used for the videos, and now it shows a list of potentially interesting books on the same topic.

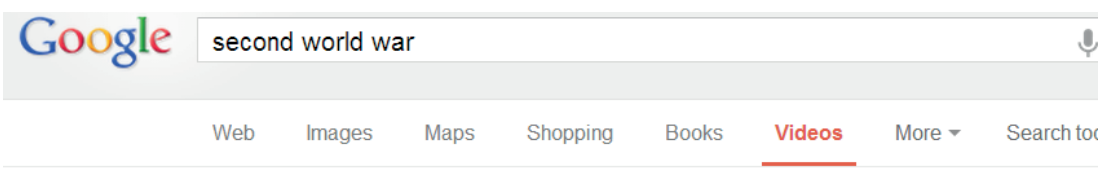

About $306,000,000$ results $(0.34$ seconds)

World War II: Definition from Answers.com

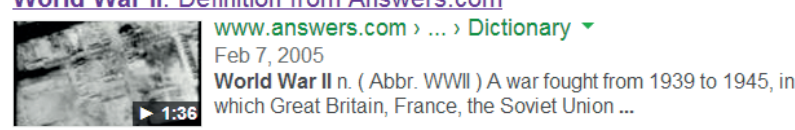

Apocalypse The Second World War SHOCK PART 1 - YouTube

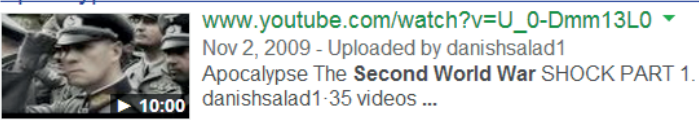

Second World War in Colour - Battle of Midway - 1st part - YouTube

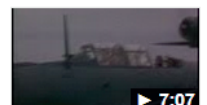

www.youtube. $\mathrm{com} /$ watch?v=oBP0kpy $46 \mathrm{bs}$ -

Oct 30, 2009 - Uploaded by Petr Warry

please DO NOT post any insulting, abusive, silly,political, religi ous nor

neo nazi comments, many thanks for that ...

Figure 2.54: Sample results page of Google Videos

Google second world war
\[ \text { Web Images Maps Shopping Books More }- \text { Searchtools } \]

About $24,100,000$ results ( 0.37 seconds)

European Memories of the Second World War

books.google.com/books?isbn=1845451589
Felmut Peitsch, Charles Burdett, Claire Gorrara - 2006 - Preview
Focusing on the growth of racism in large cities and urban areas, this volume represents
views by scholars from around the world, who work in different social sciences, on the

one hand; on the other, it offers statements by non-practicing

The Second World War: A World in Flames

books.google.com/books?isbn=1841768308
2004 - Preview
Uses contemporary documentation, private writings, and historical research to assess
the military, political, and historical significance of World War II.

The Second World War: Europe and the Mediterranean

rissacong books.google.com/books?isbn $=0757001602$

Jis

From the prewar development of the German war machine to the ultimate victory of the

Allied coalition, here is an in-depth analysis of the battles that raged on the Western

and Eastern Fronts.

Figure 2.55: Sample results page of Google Books 
Moreover, if you click on some of the links, you will see that Google has scanned some pages of the books, so you can start reading them on-line. That way, you can choose whether this is the book that you want to buy (in paper or download the full e-book) or if you would prefer to keep exploring other possibilities.

I would like you to explore all these possibilities. Even more, why don't you try to click on the upper menu on the "Images" word? What has happened? Please, remember this book is not a novel, turn your computer on, and try it! Perfect! You did it! Yes, you can also search images on the topic!

\subsubsection{Google Sites to Create Your Own Website and Google Blogger for Blogs}

We will be talking about Google possibilities more in this book, as you can imagine they are not limited to levels 1 and 2 of Bloom's taxonomy. However, for now, we will see our last two Google Apps for this chapter. They are a little more advanced because they allow you to create your own website (Google Sites) and your own blog (Google Blogger). I will help you finding these apps and using them!

To log in to Google Sites, you need to type https://sites.google.com/ in your browser. If you do that, you go to the webpage shown in Figure 2.56.

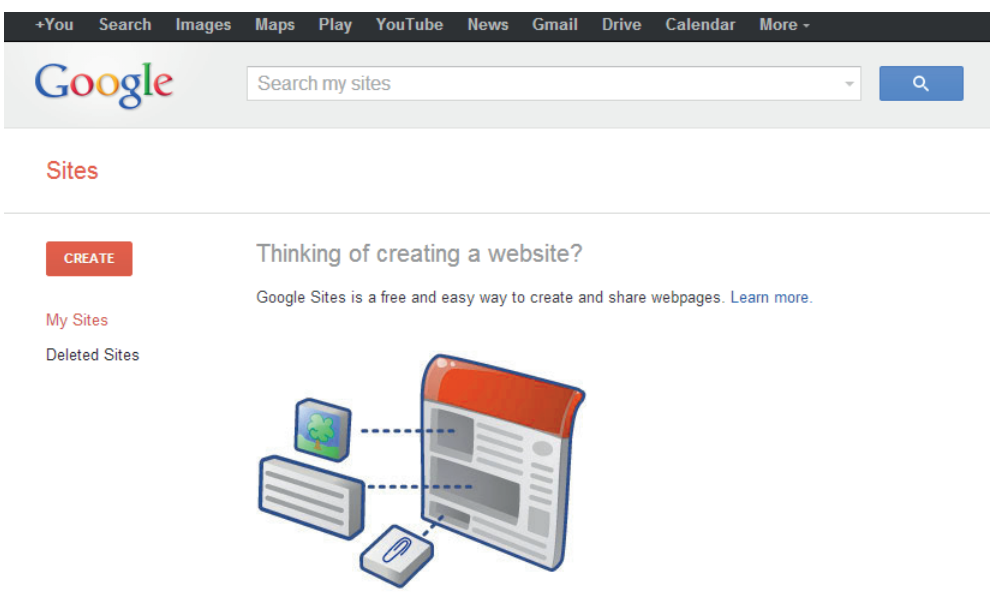

Figure 2.56: Main page of Google Sites

To create a site, you just need to click on the "Create" red button on the left. The first configuration options are shown in Figure 2.57. As you can see, you can select a template (the background of the site, same as the theme for presentations and forms in Google Drive), just by clicking on the chosen one (I will choose "Classroom site"). 
Type a name for the site, and the link to your webpage will be https://sites.google. com/site/ and the name you provide (well, if it has not already been used by another user, if so, try a different name, or combine it with some numbers like the year or your number of students. I am going to call it “salymer2013”!).

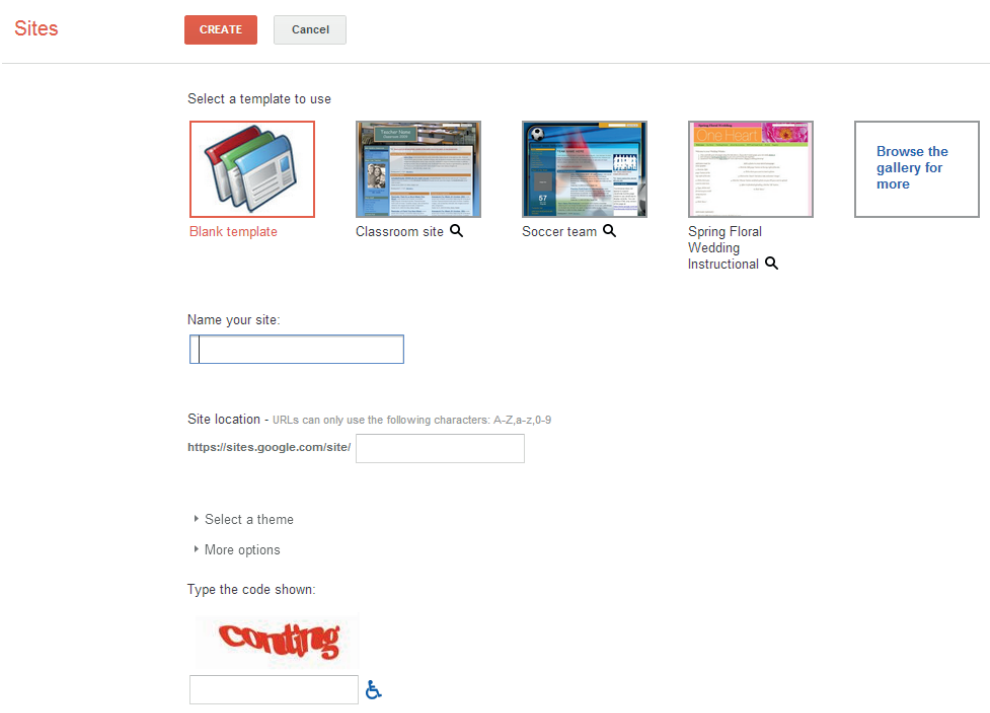

Figure 2.57: Creating a site in Google Sites

Finally, to prove that you are not a robot, do not forget to type the letters and numbers you see in the kaptcha (well, if you cannot see the kaptcha very well, do not worry if you make a mistake, Google Sites shows you an easier kaptcha) before clicking on the "Create" red button (at the top) or "Cancel" if you no longer want to continue creating the webpage. You can see in Figure 2.58 what you have been able to do in 5 seconds! Congratulations!

As you can see, you can now edit everything in the site. When you click on the "Pencil" button on the right upper corner, you will go to the edition page. In this page, you can select what you want to remove, modify or insert images, links, tables, gadgets and any Google resource (calendar, video from Youtube, etc.) as shown in Figure 2.59.

You can read more about how to change the template, and edit it, on the help pages published at: https://sites.google.com/site/sitetemplateinfo/tips/customizeyour-site-sidebar and also at this site: https://sites.google.com/site/sitetemplateinfo/ tips. When you finish your changes, you have to click on the "Save" button. As always, you can share the link, by clicking on the "Share" button, with your contacts in social networks, or just by sending the link (in our sample case, 


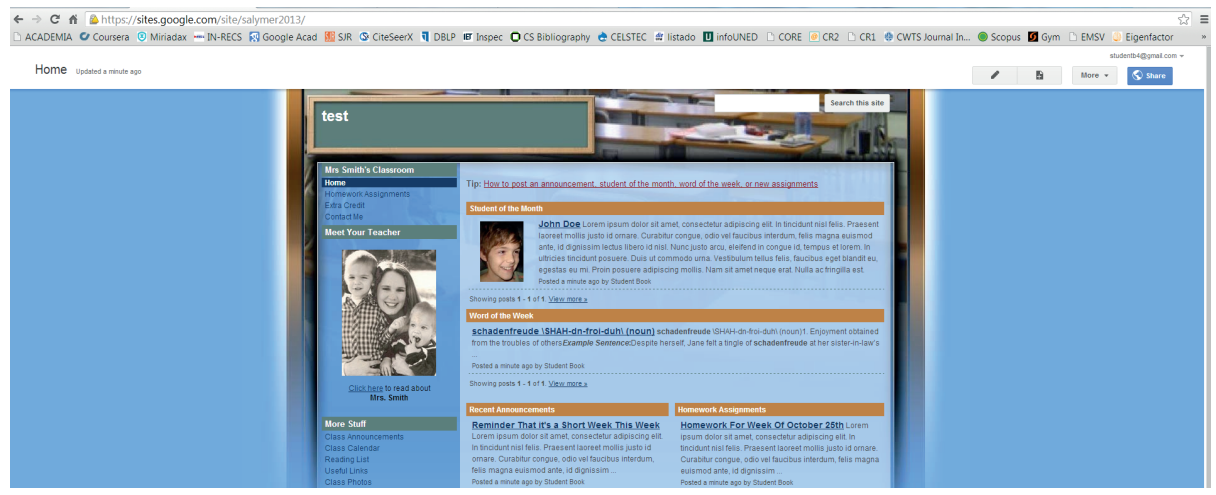

Figure 2.58: Sample site created from a template in Google Sites

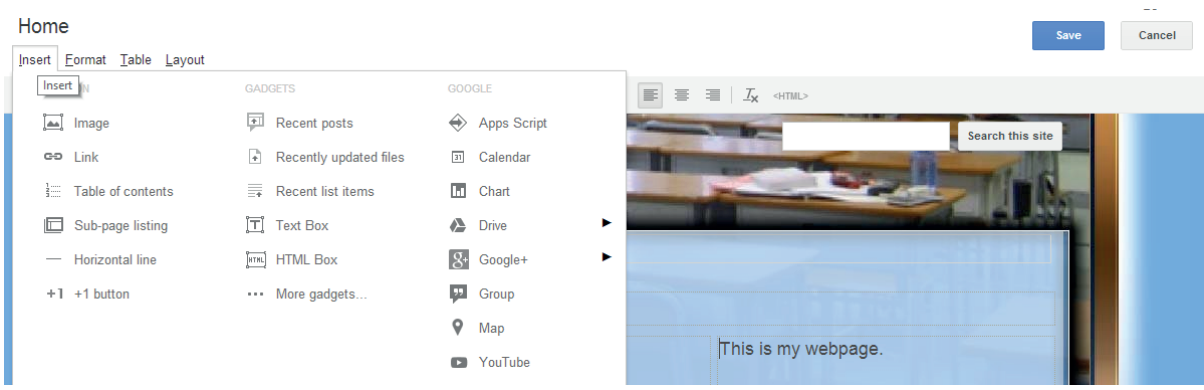

Figure 2.59: Edition possibilities in Google Sites

https://sites.google.com/site/salymer2013 ) by mail. It is already on-line, so anyone with the link can look at the website! If you want to learn more, you can read the interesting book written by Teeter \& Barksdale (2009).

Let's now go back to Figure 2.31. We have explored the options "Mail”, "Images", "Drive", “Calendar”, and we have already clicked on "More” for "Videos" and "Books", can you see now the "Blogger option"? Yes, it is there below the "More" option. If you click on "Blogger" you will see a page similar to the one shown in Figure 2.60.

If we sign in, the first question will be about our profile. We can use our Google+ (the social network part of Google) profile, or if we do not have a profile, we can create a Google Blogger profile, just by typing your name and choosing whether you would like to receive news about the blog. Once the profile is complete, we click on the orange "Continue" button. Google Blogger gives us the option to explore some existing blogs to have an idea of what a blog looks like. For example, Figure 2.61 shows a sample blog ${ }^{25}$ created with Blogger (there are many other tools!).

25 http://coolcatteacher.blogspot.com.es/ 
G Blogger

Create a blog. It's free.
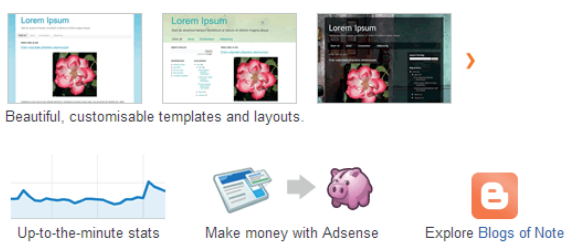

\section{Sign in}

Email

studentb4@gmail.com

Password

\section{Sign in}

Can't access your account?

Sign out, and sign in as a different user

Want to learn more? Take a quick tour, watch a video tutorial or read Blogger Buzz.

Figure 2.60: Main page of Google Blogger

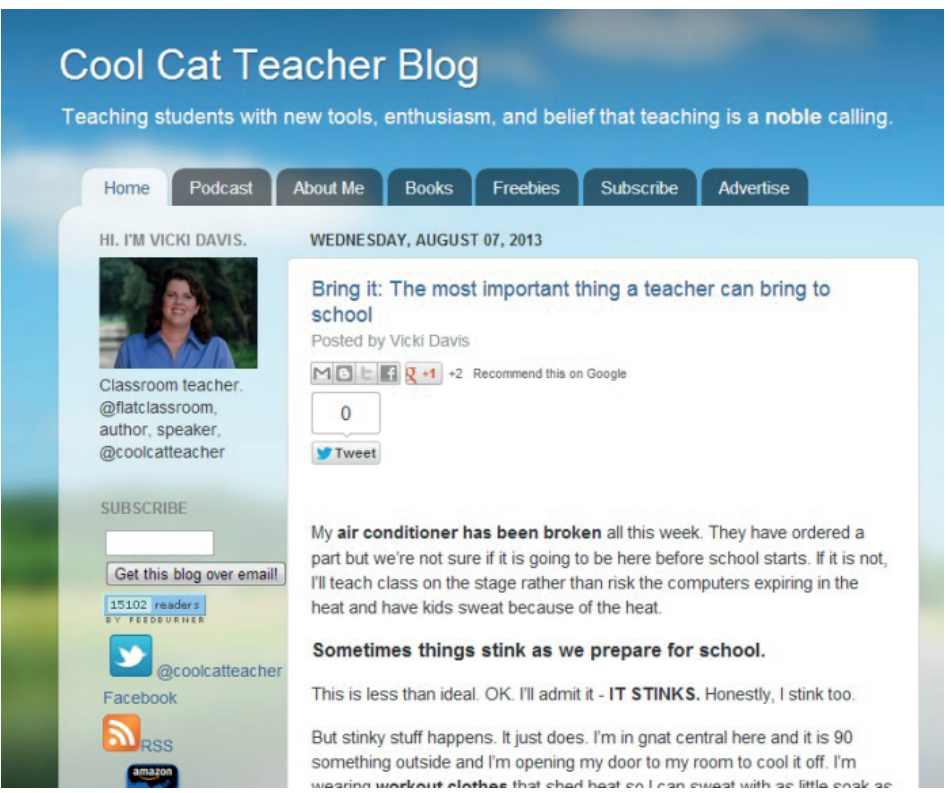

Figure 2.61: Sample blog for education (edublog)

As you can see, it is like a webpage, with the information ordered chronologically. It shows the opinion of the main writer of the blog (in this case, Vicki Davis) and the opinions of other people, some from social networks, others just readers of the blog who like to comment on the posts made by Vicki.

Let's now create our first blog. If you already know how to do that, you can skip this part, and go to Section 2.5. Otherwise, keep reading and have your computer on! Figure 2.62 shows the first step, which is to choose a name and pick a template for the blog (pretty similar to the webpage, isn't it?). 


\section{Blogs List > Create a new blog}

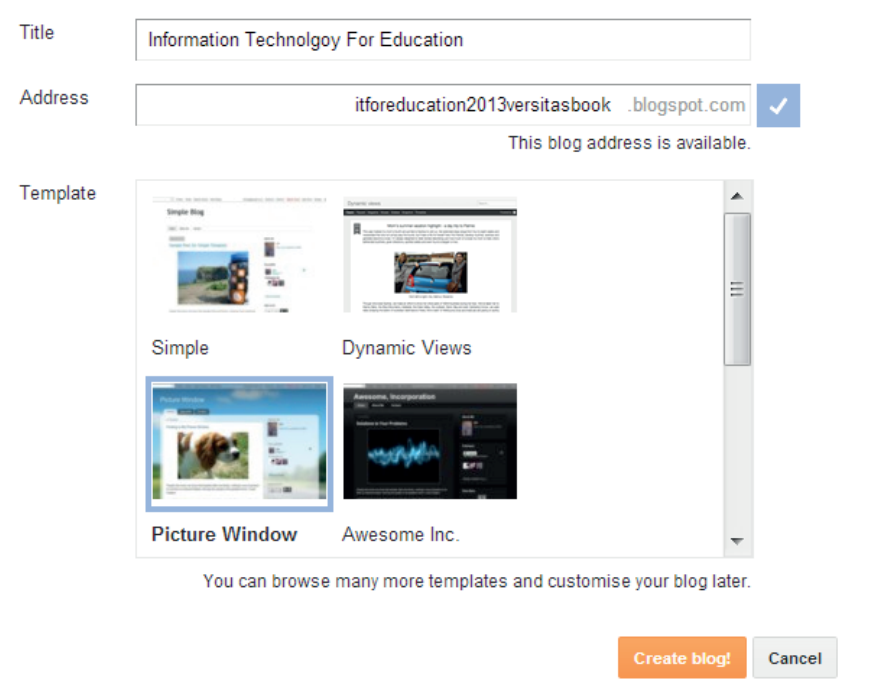

Figure 2.62: First step to create an edublog with Google Blogger

Once you click on the "Create blog!" orange button, you have it! You just need to click on "Start posting" or the pencil icon to start writing your first post in your blog. Let's write something like "This is our first post. I hope you enjoy this blog in which I will share with you information about the use of technology for education”. Figure 2.63 shows the processing options for the post. As you may recall from Google Drive when creating a document, you can edit the font, format, size, insert an image, etc. (as I said earlier this is the good thing about using tools from the same company, they are all alike!). When you finish, you just need to click on the "Publish" button in the upper right corner.

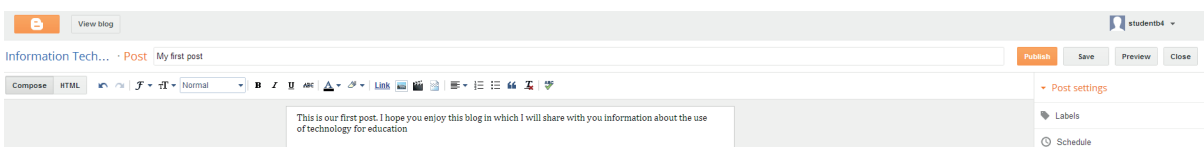

Figure 2.63: Second step to create an edublog with Google Blogger: to post something

At any time, you can see how your blog looks by clicking on the "View blog" button (at the top just next to the Blogger icon, which you can click to go back to the home page as usual). Figure 2.64 shows how your blog looks, according to the template and post provided. 


\section{Information Technolgoy For Education}

THURSDAY, 8 AUGUST 2013

My first post

This is our first post. I hope you enjoy this blog in which I will share with you information about the use of technology for education

Posted by studentb4 at 02:34 No comments:

ME $\in$ [ $8+1$ Recommend this on Google
BLOG ARCHIVE

V 2013 (1)

v August (1)

My first post

ABOUT ME

E studentb4

View my complete profile

Home

Subscribe to: Posts (Atom)

Figure 2.64: Third step to create an edublog with Google Blogger: to view your blog

Well, it is pretty awesome! It looks really nice and it was not so difficult, was it? Now, you can share the link to your blog, wait for some comments, and write more posts. It is your blog and it is already on-line. You can see a sample blog at http:// itforeducation2013versitasbook.blogspot.com.es/, and even create your own blog.

\subsection{Dropbox}

Google Drive is useful for saving files, so that you, and the people that you invite, can access them from any device connected to the Internet. Dropbox is similar to Google Drive. You may be wondering why I would like to show you Dropbox. Well, because it is really popular. Your students may use Dropbox instead of Google Drive, and it is good to know about Dropbox, too. The good thing is that once you know how to use Google Drive, Dropbox ${ }^{26}$ is really easy. The concept is similar, to have documents on-line that you can use and share from any device connected to the Internet. You are given a limited amount of space, and you can get more free space if you invite people to use Dropbox. It is a web application, but you can download the desktop program so that you can have it as a folder in your hard disk. The difference is that everything you save in this folder will also be saved on-line, so you can access it from any device connected to the Internet.

26 https://www.dropbox.com/ 
If you do not have a Dropbox account, then as usual, first of all, you need to get one. It is free and it is just necessary to fill in the form. You can download the desktop application to your computer, and check how it synchronizes with the web information with a little blue circle. Whenever, the information in your computer is the same as the information on-line then you can see a little green check. Do not close your computer until there is the green check, and thus, Dropbox has finished uploading everything you save in the folder so that it is available in another device connected to Dropbox. Sometimes it can take a while to upload everything if you have saved many files or have very big files. So, always look for the green check!

Let's see a sample use of Dropbox step-by-step. Imagine that I have a report, and now I want to create a folder in Dropbox to share it with my 2 friends, Eva and Tom, who are working with me on a common project. I have already registered in Dropbox, and downloaded the Desktop application. So, in my computer I can see next to the time, on the lower right corner, the Dropbox icon with the green tick, as you can also see in Figure 2.65 .

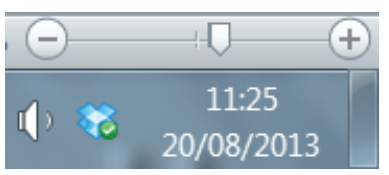

Figure 2.65: Dropbox installed in your computer and correctly synchronized (green tick!)

First step. To create a folder in Dropbox. You can click on the icon, or directly in the folder called "Dropbox" created in your computer when installing the Dropbox application. As you can see, it seems to be a normal folder, like the rest of the folders in your computer, except for the green ticks. So, you can create a folder using the "New" -> "Folder" option of the menu that appears when you click with the right button of the mouse, and you can give it the name "projectTomAna", as shown in Figure 2.66.

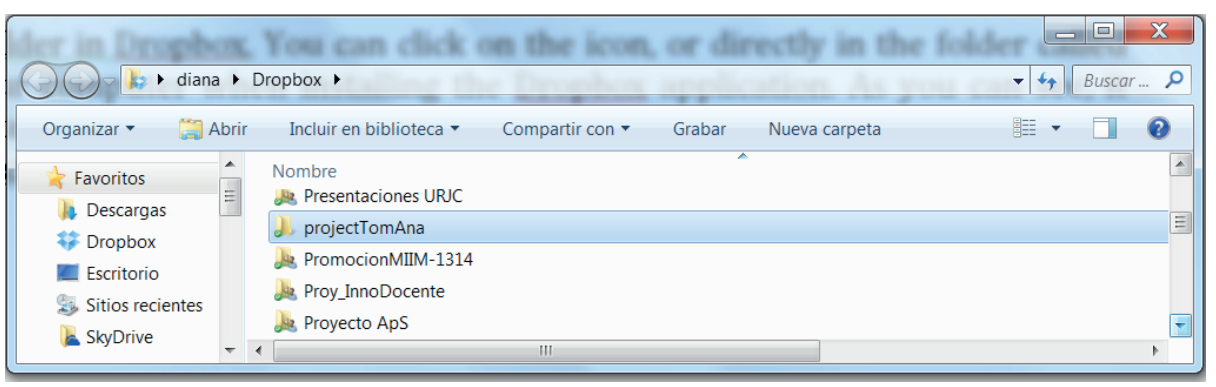

Figure 2.66: Dropbox sample folder "projectTomAna” (in the computer) 
Do you want to see how the folder is also created on-line? You can go to dropbox.com and $\log$ in with your user and account password. As you can see the folder appears initially as "folder" and it is empty. See Figure 2.67.

盢 https://www.dropbox.com/home

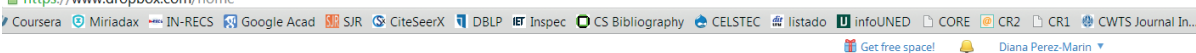

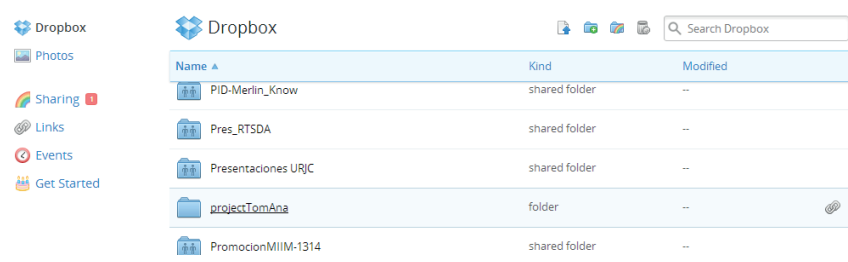

Figure 2.67: Dropbox sample folder “projectTomAna” (on-line)

Second step (optional). To share a folder in Dropbox. This step is optional, because you can create the folder and start using it like any other folder, with the advantage that you can access everything you save inside on-line. However, it is common that you would want to share the content with some other people in your team. In this case, we are working with Tom and Ana, so let's share the folder with them. The easiest procedure is to click with the right button on the folder, as shown in Figure 4.18, and then click on "Invite to folder" as shown in Figure 2.68. Next, you import the contacts or write the e-mails to the people you want to invite and a short description (they will get a mail giving them more information about the request). See Figure 2.69 for an illustration of how you add contacts.

When you click on the shared button, then you can see a message indicating that the folder has been shared. So, now whatever file they save in the folder, you can work on it, and vice versa. Take care with deleting files, because you can delete them on all the devices connected to the Internet sharing this folder!

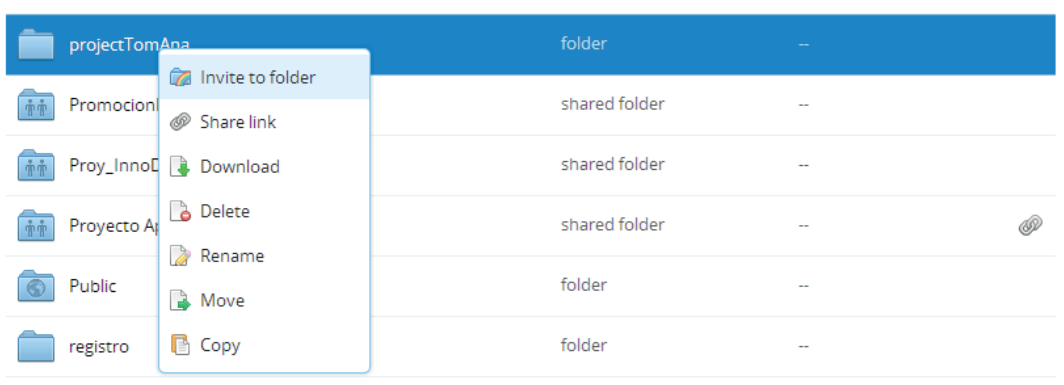

Figure 2.68: Inviting other people to use a folder in Dropbox (I) 
Share 'projectTomAna' with others

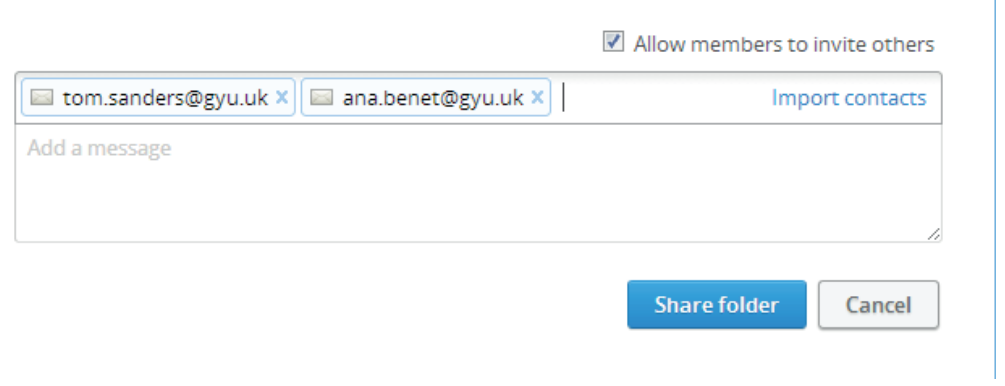

Figure 2.69: Inviting other people to use a folder in Dropbox (II)

Third step (optional). To make a link publicly available to everyone. Again, you may want just to limit the files to your team group, and then when you finish, to make the final document public, or not. If you want your document to be seen by anyone, you have to save the file in the "Public" folder that is created by default in Dropbox. When you do that, you are given a link which allows everyone on the Internet access to the file. To get the link, you have to click on the file, and with the right button select the option "Copy public link" as shown in Figure 2.70.

(?) Copy public link

To share this file with others, copy and paste this link: Shorten link
https//dl.dropboxusercontent.com/u/12353669/agente.zip

Copy to clipboard Cancel

Figure 2.70: Public links in the public folder of Dropbox for everyone

If you do not want to share the file any longer, you can delete it, just by clicking on the file. Moreover, you can upload more files to the web by clicking on the link with the blue arrow, and then creating new folders by clicking on the folder with the green plus. That way, teachers, students, and everyone else can keep working from any device with their Dropbox account. Please, explore the many possibilities of this wonderful tool, encourage your students to use it, do not forget to log out when you have finished using it, and enjoy it! 


\subsection{Exercises}

Let's do several exercises to practise the content of this chapter. Remember that all exercises are solved at the end of the chapter, but do not read the solutions until you have tried to solve the exercises on your own first! It is also possible that you may find other answers to these questions; in that case, you can let us know about them on the book website.

1. Search on the Internet for five education portals.

2. Provide five reasons why a teacher could benefit from using an education portal.

3. Provide five reasons why a student could benefit from using an education portal.

4. Discuss some advantages and disadvantages of using education portals.

5. Join a MOOC, and describe your experience in the book forum. What have you found most useful? Have you found anything difficult?

6. Provide ten reasons why a teacher could use Google Apps for Education.

7. Fill in the blank spaces in the following sentences with the name of a Google App:

a) I can read and compose mails with ...

b) I can organize the agenda of events in my class with ...

c) I can create a shared presentation on-line with ...

d) I can find a video on-line with...

e) I can create my own website with...

f) I can create my own blog with .....

8. Upload a document downloaded from a MOOC to a folder that you have created in Dropbox.

9. Which of the following statements are true and which are false?

a) You can upload a folder to Dropbox.

b) You need to download the Dropbox desktop application to access your files in Dropbox.

c) There are a maximum number of files that you can save in Dropbox.

d) It is possible to create an Access link to a Dropbox folder in your desktop.

\subsection{Solved Exercises}

1) Discuss in the forum the education portals you found. I am just going to give you a link where you can find many education portals: http://eduscapes.com/tap/topic21. htm

2) My five reasons would be the following (remember this is a subjective question so you could have different reasons, and it would be really nice if you shared them with your colleagues in the book forum):

1. To get high quality education resources organized into levels and topics.

2. To access free services such as search engines or newsletters. 
3. To read about the experiences of other teachers.

4. To collaborate with other teachers and students.

5. To get some IT, legal or any other type of counseling.

3) My five reasons would be the following (remember this is also a subjective question so you could have different reasons, and it would be really nice if you shared them with your colleagues in the book forum):

1. To provide your students with more resources to learn about the topic under study.

2. To learn in an interactive way on-line.

3. To get advice from your peers.

4. To collaborate with other teachers and students.

5. To enjoy learning with fun activities on-line.

4) Again, this is subjective, I will just give you some advantages and disadvantages I see in using education portals, but you may have others, and what could you do with them? Yes, that would be great! Thanks! You could publish them on the book website to share them with other readers!

Some advantages of using education portals are the following:

1. To provide information to teachers, students and parents.

2. To offer a free content search engine.

3. To provide free high-quality didactic resources.

4. To contribute to teacher training.

5. To provide counseling.

6. To open collaboration channels.

7. To allow new time and place flexibility for learning, something that only the Internet can provide.

Some disadvantages of using education portals are the following:

1. To waste time just looking at hundreds of education portals several times per day.

2. To replace some face-to-face learning because it is already on-line. It is not the same!

3. To have some technological problems because of broken links or the lack of usability.

4. To lose information without further notice because the education portal disappears.

5) I joined MiriadaX, the platform for Spanish MOOCs. I created a MOOC there, and I joined other MOOCs. In particular, there was a MOOC about Emotional Intelligence that I found really interesting. I followed the steps provided in the chapter. I avoided enrolling in too many MOOCs, I knew I did not have the time to successfully complete 
all of them. So, I focused on the Emotional Intelligence MOOC. Every Friday morning, I logged into the MOOC, I saw the materials, and I did the quizzes. What did I find the most difficult? To be sincere, it was difficult for me to keep updated with all the posts in the forum. I decided to read just some of them, and I filtered all the information according to my needs. All in all, I think it was my best choice because reading all this information was impossible, and I would have not enjoyed the MOOC so much. How was your experience? Please, share it on the book website. You do not need to write much, perhaps one paragraph like the one I have just written.

6) According to Google, but you may have other reasons, the ten top reasons for using Google Apps for education are the following:

1. Students will love you for it

2. Free up your IT

3. Easy to deploy

4. Save money

5. You're not alone

6. Google protects your privacy

7. Security as powerful as... well, Google

8. Innovation in real-time

9. Collaborate globally

10. We've got your back

7) The complete sentences would be the following:

a. I can read and compose mails with Gmail.

b. I can organize the agenda of events in my class with Google Calendar.

c. I can create a shared presentation on-line with Google Drive.

d. I can find a video on-line with Google Video.

e. I can create my own website with Google Sites.

f. I can create my own blog with Google Blogger.

8) To upload a document to Dropbox is pretty simple. If you are using the computer on which you downloaded Dropbox, you just need to save it in your Dropbox folder. Otherwise, you can log in with your username and password and upload it by clicking on the icon with the up arrow. Remember that you need to see the green tick in your Dropbox folder to make sure that the file has been correctly uploaded. In the case of the web application, there is no problem because the progress bar lets you know when the upload is finished.

9) True or false?

a) You can upload a folder to Dropbox. $\rightarrow$ True, you can copy the folder into your Dropbox folder. 
b) You need to download the Dropbox desktop application to access your files in Dropbox. $\rightarrow$ False, you can access your files on-line from any computer, even if that computer does not have Dropbox installed.

c) There are a maximum number of files that you can save in Dropbox. $\rightarrow$ True, but not because Dropbox counts how many files you upload, but because there is a maximum amount of space that you have on-line, you can check the $\%$ of your Dropbox account that is still free in your folder. You can get more space by inviting friends to Dropbox!

d) It is possible to create an access link to a Dropbox folder on your desktop. $\rightarrow$ True, the Dropbox folder in your computer is like any other folder, with the difference that anything you save inside is also uploaded to the Internet so that you can access those files from any computer connected to the Internet.

\subsection{References}

Last visit to all links on August 14 ${ }^{\text {th }}, 2013$

Bedriñana-Ascarza, A. (2005), Técnicas e indicadores para la evaluación de portales educativos en Internet, Gestión en el Tercer Milenio, Research Journal UNMSM 7(14).

Daniel, J. (2012). Making sense of MOOCs: Musings in a maze of myth, paradox and possibility. Journal of Interactive Media in Education, 3. Available on-line at http://www-jime. open.ac.uk/jime/article/viewArticle/2012-18/html

Darbyshire, P. (2010). Getting StartED with Google Apps. Apress.

Holzner, S.; \& Holzner, N. (2009). Google Docs 4 Everyone, Pearson Education.

Koutropoulos, A.; \& Hogue, R. J. (2012). How to Succeed in a MOOC-Massive Online Open Course. Newsletter, CEdMAEurope. Available on-line at http://www.cedma-europe.org/newsletter\%20 articles/eLearning\%20Guild/How\%20to\%20Succeed\%20in\%20a\%20MOOC\%20-\%20 Massive\%200nline\%200pen\%20Course\%20(Oct\%2012).pdf Lamont, I. (2013). Google Drive \& Docs in 30 Minutes. 130 Media Corporation. McAuley, A.; Stewart, B.; Siemens, G., \& Cormier, D. (2010). The MOOC model for digital practice. Technical Report. University of Prince Edward Island. Available on-line at https://oerknowledgecloud.org/sites/oerknowledgecloud.org/files/MOOC_Final_0.pdf

Teeter, R.; \& Barksdale, K. (2009). Google Sites and Chrome For Dummies. John Wiley \& Sons Ltd. Weinschenk, S. (2012). 100 Things Every Presenter Needs to Know About People. New Riders. Yilmaz, M. (2013). An Essential Guide to Google Drive, Amazon Media (Kindle book).

\section{Other interesting links to keep reading (there are many more!)}

https://www.learntogether.org.uk/Pages/Welcome.aspx

http://www.dhsekerala.gov.in/

http://www.thutong.doe.gov.za/

https://www.dias.ac.cy/en/Pages/intro.aspx

http://www.ciconline.org/

http://eduscapes.com/ 
http://www.epals.com/

http://www.elearningeuropa.info/en/articles

http://eduscapes.com/tap/topic21.htm

https://www.edx.org/

https://www.coursera.org

https://www.udacity.com/

https://www.miriadax.net/

https://unedcoma.es/

http://edutraining.googleapps.com/Training-Home/module-1/module-1-chapter-1 